THE LONDON SCHOOL

OF ECONOMICS AND

POLITICAL SCIENCE

\title{
The Redistributive Effects of Pandemics: Evidence of the Spanish Flu
}

Sergi Basco, Universitat de Barcelona Jordi Domenech, Carlos III de Madrid and Joan R. Roses, LSE

Mav 2020 


\title{
The Redistributive Effects of Pandemics: Evidence on the Spanish Flu *
}

\author{
Sergi Basco \\ Universitat de Barcelona
}

\author{
Jordi Domènech \\ Carlos III de Madrid
}

Joan R. Rosés

London School of Economics

This version: May 2020

\begin{abstract}
This paper examines the impact of a pandemic in a developing economy. Measured by excess deaths relative to the historical trend, the 1918 influenza in Spain was one of the most intense in Western Europe. However, aggregate output and consumption were only mildly affected. In this paper we assess the impact of the flu by exploiting within-country variation in "excess deaths" and we focus on the returns to factors of production. Our main result is that the effect of flu-related "excess deaths" on real wages is large, negative, and shortlived. The effects are heterogeneous across occupations, from null to a 15 per cent decline, concentrated in 1918. The negative effects are exacerbated in more urbanized provinces. In addition, we do not find effects of the flu on the returns to capital. Indeed, neither dividends nor real estate prices (houses and land) were negatively affected by flu-related increases in mortality. Our interpretation is that the Spanish Flu represented a negative demand shock that was mostly absorbed by workers, especially in more urbanized regions.
\end{abstract}

Keywords: pandemics, Spanish flu, real wages, returns to capital JEL Classification: E32, I00, N10, N30

*E-mails: sergi.basco@gmail.com, jdomenec@clio.uc3m.es, j.r.roses@lse.ac.uk 


\section{Introduction}

Which are the economic consequences of pandemics? How are the losses shared between workers and owners of capital? Are these effects persistent over time? Do they differ across regions? All these questions have become relevant after the outburst of confirmed cases and deaths of Covid-19 across the globe. In this paper, we attempt to answer these questions by analyzing the effects of the so-called "Spanish" flu in 1918 within Spain. Figure 1 reports the evolution of the number of deaths in Spain between 1910 and 1930. The effect of the Spanish Flu on mortality is apparent from the figure. In 1918, there was a 54 percent increase in the number of deaths, relative to the pre-1918 average. To put this number into perspective, around 3.5 percent of the Spanish population died in 1918, with an estimated increase in deaths caused by influenza of 260,000 deaths. The flu itself increased the mortality rate relative to the historical trend by 75 per cent.

Spain is an optimal country to examine the economic effects of the Spanish flu. First, in contrast to industrialized countries, Spain was neutral in World War I, which mitigates the bias induced for military spending and other side effects of the war. Second, early 20th century Spain was a very heterogeneous country (Rosés et al. (2010)). The levels of income and industrialization widely varied across provinces, which will help us to extrapolate from our results potentially heterogeneous effects of pandemics across countries at different levels of development. Third, the level of economic development in Spain was high enough to have good reliable data on real wages and proxies for the returns to capital across time and provinces to perform this exercise.

When evaluating policy reactions to the pandemic, given the economic and logistic costs of massive testing, the crucial trade off seems to be between enforcing strict social distancing to avoid excessive deaths and the damage done to the economy by the collapse of consumption and unemployment caused by drastic quarantine measures (Hollingsworth et al. (2011); Anderson et al. (2020); Acemoglu et al. (2020); Lin and Meissner (2020)). In many developing countries, social distancing is difficult to enforce due to cramped housing and the lack of safety nets (meaning the poor must work in the midst of the pandemic). In less democratic contexts, elites can shield themselves from the pandemic both physically and politically, meaning social distancing is more loosely enforced. The policy equilibrium in these contexts might consist of less drastic social distancing and higher mortality, but perhaps a milder downturn. This seems to be the case of Spain in 1918. Although in global comparisons, the flu in Spain was less deadly than in India or Indonesia, still the mortality rate was more than double the rate of other Western European countries. In contrast, a drastic contraction of output is not apparent in the data.

There seems to be a consensus that pandemics tend to equalize societies (Scheidel (2017)). The evidence reported in Jordà et al. (2020b), using a cross-section of countries dating back to the 14th century, is consistent with this view. Indeed, they document that pandemics tend to 
increase real wages and depress returns to capital (also in the long-run). A potential concern is that these results are driven by ancient episodes and do not apply to the Spanish Flu. There is no evidence for the particular case of the Spanish Flu. The closest exercise is Barro et al. (2020), who use a cross-section of countries and fails to document an effect of the Spanish Flu on stock market returns. We will exploit within-country variation in the increase in the number of deaths to empirically assess the re-distributive effects of the Spanish Flu in the short and medium-run. To perform this exercise, we have data on real wages and two proxies for returns to capital (dividends and real estate prices).

A related question is the mechanism through which pandemics affect economic activity in the short-run. A definitive answer to this question is outside the scope of this paper due to data limitations. However, by analyzing the heterogeneous effects across occupations and regions, we can provide a tentative answer. Theoretically, pandemics can be thought of as a supply shock because the labor force is reduced by death, sickness or social distancing and production declines. They can also represent a demand shock because consumption declines as uncertainty about the future and unemployment increases. ${ }^{1}$ If the demand-shock is driving the results, we would expect that the effects of the flu were exacerbated in occupations and regions hit by larger consumption declines. In our context, this should happen in occupations related to non-essential consumption and in more urbanized regions with greater awareness of the dangers of the flu and stricter social distancing .

Our main contribution is to show that most of the losses due to the Spanish Flu were absorbed by workers. Indeed, the intensity of the flu in each province reduced daily real wages for all occupations. This underestimates the full impact of the flu on workers' incomes, as workers who kept their jobs may have worked fewer days during the peak months of the pandemic. In contrast, we find dividends and real estate prices (our proxies for the return to capital) were not negatively affected. We also show that the decline in real wages was short-lived, with some exceptions (tailors and shoemakers). In addition, the negative effects were stronger in more urbanized provinces (with higher population density), where the decline (or delay) of consumption in non-essential goods may be larger. We interpret this overall evidence as supporting the hypothesis that the Spanish Flu mostly represented a negative demand shock.

To proxy for the intensity of the pandemic, we obtain data at the province level of the number of deaths by year from INE Historical Database (Spanish National Institute of Statistics). Our measure of the Spanish Flu is "excess death rate" in the province, given by the difference between the actual number of deaths and the number of deaths predicted by a province-specific linear trend and normalized by the population size of the province. As it can be seen from Figure 1, the number of deaths was relatively stable between 1910 and 1930, except in 1918. "Excess death rate" is generally zero in all provinces except in 1918, when it suddenly increased.

\footnotetext{
${ }^{1}$ Guerrieri et al. (2020) formally derive a theoretical model to understand the macroeconomics effects of Covid-19 and argue that a supply shock can actually become a Keynesian demand shock.
} 
When we analyze if the flu had persistent effects in a differences-in-differences setting, we just use excess mortality in 1918 interacted with year dummies.

The core of the paper is to examine the effect of cross-sectional and temporal variations of mortality on real wages. We have data for nine different occupations: agricultural workers, builders, stone-cutters, carpenters, blacksmiths, metal workers, painters, tailors and shoemakers. We combine this with cost-of-living indices for each province-year dyad. When we regress annual growth rate of real wages on the province-year deviation of mortality from its linear trend, we find that the effect is negative and statistically significant for all occupations, except for agricultural workers. All regressions include province and year fixed effects. Quantitatively, an increase in one percent in "excess death rate" results into a decline of real wages between 12 per cent (shoemakers) and not significant (agricultural workers). When we focus on excess mortality in 1918 and compute the decline with respect to the pre-1918 period, we find that the average effect was a decline in real wages that ranges from no-effect for metal workers to around 25 and 35 percent for tailors and shoemakers, respectively. We also document that these negative effects on real wages were, in general, short-lived. That is, after the initial negative shock (1918), real wages recovered, offsetting the initial negative shock. The only exception are tailors and shoemakers, which do experience a negative persistent shock. These results are robust to alternative specifications and definitions of real wages, winsorizing "excess deaths", weighting the observations by population size, removing Barcelona and Madrid from the sample (the wealthiest provinces) and making adjustments to the dependent variables to control for spatial auto-correlation.

We also document heterogeneity of the effects on real wages across provinces. The negative effect is exacerbated in more urbanized provinces. Because these provinces had actually lower mortality rate (relative to the province-specific trend), our interpretation is that in these provinces people were more aware of the dangers of the flu and kept stricter social distance measures. The fact that the exacerbation effect of population density is relatively larger in tailors and shoemakers lends additional evidence on this demand-driven hypothesis. Moreover, we fail to find any exacerbation effect in more industrialized provinces. We view this result as evidence against the supply-driven hypothesis. We would expect that in more industrialized provinces an increase in excess mortality should have reduced job competition and mitigate the negative effect on wages. Therefore, this evidence on the heterogeneity on the results paints a picture consistent with the demand driven interpretation.

In addition, we investigate the effects of the flu on the returns to capital. We do not have an annual series of the returns to capital at the province level. However, we have two measures that proxy for capital returns. First, we have data on the evolution of dividends paid by public companies. We find that excess mortality does not have any effect on dividends. Real estate prices is our second proxy for rents. As documented in Jordà et al. (2019), housing seems to be the most important asset throughout history, the Spanish case is no exception (Prados de la 
Figure 1: Evolution of Number of Deaths in Spain, 1910-1930

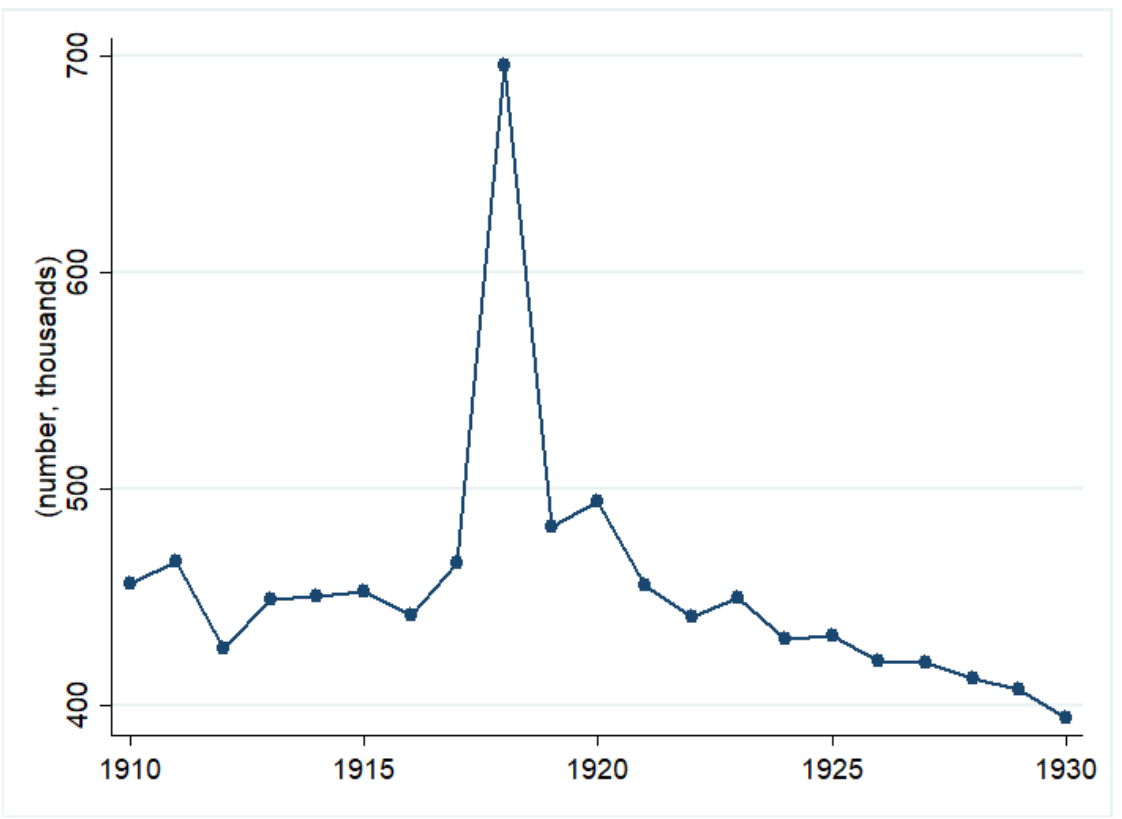

Sources: Death data obtained from INE Base Histórica.

Escosura and Rosés (2010)). Thus, changes in housing prices could be a good proxy of returns to capital in early 20th century Spain. In addition, we consider land prices. We do not see land prices as proxies for the returns to land ownership. Rather, we view them as another asset class to approximate the returns to capital. The estimated coefficients on "excess deaths" reject the hypothesis that the effect of the flu on either housing or land prices is negative. Thus, the conclusion from these analyses is that the Spanish Flu had no significant negative effects on capital returns.

Our interpretation of the results is that the Spanish Flu represented a large demand shock that was not persistent over time. The losses were concentrated among workers which experienced a substantial reduction in real wages; whereas returns to capital did not significantly change. One potential mechanism is that, due to uncertainty and social distancing, consumption in non-essential goods declined. Firms reacted to this decline in demand constraining real wage growth. We leave for future research to empirically investigate this channel.

Will this time be different? It is too soon to assess whether the redistribution and persistence of the effects of Covid-19 will be the same as the effects of the Spanish Flu. The fact that the decline in real wages was exacerbated in more urbanized provinces, suggests that the decline in consumption, due to social distancing, is the driver of the effects. Moreover, the finding that workers are more affected than capital earners seem likely to be repeated according to initial anecdotal evidence and economic forecasts (e.g, World Economic Outlook IMF (April 2020), and Baldwin and di Mauro (2020)). Indeed, forecasts predict large economic effects and large 
losses for workers. For instance, the huge increase in unemployment claims in most developed countries suggest that the effects will be absorbed mostly by the labor force.

Related literature Our paper relates to different strands of the literature. First, it is related to the large literature that examines the long-run effects of economic crises. This list includes, among others, Reinhart and Rogoff (2009) and Jordà et al. (2013). The type of analysis is similar, even though they focus on financial crises and here we study the effect of an "exogenous" increase in the number of deaths. It is also related to the emerging literature on the economics effect of the flu in 1918. For example, Barro et al. (2020) uses cross-section of countries and find that the flu in 1918 had an estimated effect on GDP and consumption of 6 and 8 percent, respectively, for the average country. Another related paper is Correia et al. (2020), which uses within-country variation on the US and find that the flu in 1918 had a negative effect on employment and output, while focusing on the heterogeneity on non-pharmaceutical interventions. We use the same empirical strategy as Barro et al. (2020). The main departure from this literature is that we are interested on how the economic loses were distributed within the country.

In addition, there exists a more recent empirical literature examining the economic persistence of large shocks. However, there is no clear consensus about what sort of shocks and what circumstances generate persistent effects. On the one hand, pandemics and other disasters have long run effects (Scheidel (2017); Jordà et al. (2020b)) or are more persistent than expected (Jordà et al. (2020a); Vonyó (2012)). On the other hand, there is also a large literature showing that very large shocks can be followed by quick reversions to the long run trend (Davis and Weinstein (2002); Miguel and Roland (2011)). For the particular case of the Spanish flu, most authors point at short run effects with quick reversions to trend. For the US example, although Almond (2006) has uncovered large individual effects, Velde (2020); Brainerd and Siegler (2003) document quick reversions to trend within the US. Barro et al. (2020) also documents short-run effects of pandemics using a cross-section of countries. Our paper supports this non-persistence interpretation of the Spanish flu. For Spain, we document large but short-term impacts on labor income and not significant effects on capital.

There is also a vast economic growth theory discussing the theoretical affects of population growth and its empirical validity throughout history (see, for example, Galor (2011). In a Malthusian model, it is assumed that there are decreasing returns to scale and, population growth is constrained by output growth. This is the well-known Malthusian trap or "iron law of wages", which can explain pre-industrial stagnation (Clark (2007)). In the opposite side, we find the endogenous growth literature or economics of ideas (see, Romer (1990)), in which population growth is related to new ideas, productivity and economic growth. Along this line of research, the closest paper is the recent contribution by Jordà et al. (2020b). They conduct a very large cross-country analysis on the effects of pandemics dating back to the 14th century. 
They focus, as we do, on the effect of the pandemics on real wages and return to capital. Given their time horizon, they can perform very long-run analysis that we can not do. Our contribution to this debate is limited given that we perform a shorter-term analysis for a specific pandemic and country. However, it seems that we obtain different results. Jordà et al. (2020b) isolate a Malthusian effect in which mortality crises increase real wages. Here, our results are more consistent with a increasing returns framework in which a pandemic reduces wages. Moreover, we find null effects on returns to capital, while Jordà et al. (2020b) finds negative effects for returns to capital.

Lastly, we also contribute to the economic history literature that examines the evolution of the Spanish economy in the early 20th century. Typically, the pandemic has not had a prominent role in explaining economic trends in the first third of the 20th century. Indeed, the debate has mostly centered around the impact of Word War I on a neutral economy (not positive) and on the factors driving fast structural change, catch up and industrial growth in the 1920s (Prados de la Escosura and Rosés (2009)). The pandemic is generally not mentioned as a factor affecting economic performance. In addition, when analyzing the factors driving the spatial and temporal variation in living standards in the first third of the 20th century, especially real wages, inflation, collective action and pro-worker legislation are stressed (Maluquer de Motes and Llonch (2006)), whereas the flu pandemic is not even considered as an explanatory factor. For spatial variation, World War I and de-globalization, increased wage differentials in the late 1910s, while internal mobility drove convergence in real wages in the 1920s (Rosés and SánchezAlonso (2004)). Our contribution to this literature is to include the Spanish Flu as an important variable driving temporal and spatial variation in real wages. We will show that the flu slowed down real wage growth in 1918, perhaps anticipating the social discontent of 1919-1920.

The rest of the paper is structured as follows. Section 2 describes the historical setting of Spain in the time of the Spanish Flu. Section 3 explains the empirical setting and the data. Section 4 presents the main results of the paper. Lastly, section 5 concludes

\section{The Spanish Flu in Spain}

The first news of an increasing death toll due to respiratory diseases appeared in the Spanish press in May 1918, in the wake of the first wave of the pandemic starting in March 1918. The second, much deadlier wave of flu, apparently starting in late August in France, spread to Spain via seasonal workers returning from France. This wave peaked in October 1918, with mortality rates increasing by 300 per cent with respect to the pre-influenza mortality rates in October (Trilla and Daer (2008)). A third, milder connected wave was detected in the winter of 1919. According to some existing estimates, deaths caused by respiratory diseases increased by 2.4 per 10,000 in the first wave of May-July 1918 and by 92.6 per 10,000 during the Fall 1918-Winter 1919 wave. Excess deaths from all causes in the wave Fall 1918-Winter 1919 increased by 112.9 
Table 1: Mortality rates per 1,000, Spanish Flu.

\begin{tabular}{lll}
\hline Country & Death toll & $\begin{array}{l}\text { Death rate } \\
\text { (per 1,000) }\end{array}$ \\
\cline { 2 - 2 } & 20,458 & 3.3 \\
Denmark & 12,374 & 4.1 \\
Eire & 18,367 & 4.3 \\
England and Wales & approx. 200,000 & 5.8 \\
Scotland & $27,650-33,771$ & $5.7-6.9$ \\
Finland & 18,000 & 5.8 \\
France & 240,000 & 7.3 \\
Germany & 225,330 & 3.8 \\
Hungary & approx. 100,000 & 12.7 \\
Italy & 390,000 & 10.7 \\
Netherlands & 48,042 & 7.1 \\
Norway & 14,676 & 5.7 \\
Portugal & 59,000 & 9.8 \\
Spain & $\mathbf{2 5 7 , 0 8 2}$ & $\mathbf{1 2 . 3}$ \\
Sweden & 34,374 & 5.9 \\
Switzerland & 23,277 & 6.1 \\
US & 675,000 & 6.5 \\
Mexico & 300,000 & 20.6 \\
\hline
\end{tabular}

Sources: Johnson and Mueller (2002)

per 10,000 (Chowell et al. (2014)). Mortality rates were higher in the 25-34 age group, while there were below trend among those above 65 . As a result of the pandemic, Spain's population growth was negative in 1918 (net loss of 83,121 persons). Table 1 shows how death rates in Spain were among the highest in Western Europe and North America.

We do not have at this stage much information on the adoption of quarantines and related policies to reduce the rate of infection. News on the pandemic appeared regularly in the main newspapers. King Alfonso 13th was apparently infected in the first wave of the pandemic before the summer of 1918. As mortality levels increased, La Vanguardia in Barcelona opened up with several pages of obituaries of people killed by the flu virus. Madrid newspapers like $A B C$ or El Debate provided very detailed reports of the spread of infection in the provinces. Schools and universities were closed, but mass and other gatherings were still organized, facilitating the spread of the virus. Some public health measures were adopted: streets were cleaned with water and sodium hypochlorite. Trains, tramways, baggages, bars, cafeterias, even the mail, were regularly disinfected with phenolic oil. Social distancing and disinfection measures were recommended by state authorities, but these measures were difficult to enforce. Therefore, even though mortality rate peaked in late 1918, the economic disruption, driven by increased uncertainty and fear, is likely to have started during the spring of 1918 when news and social distancing measures started to emerge. 
Figure 2: Evolution of Gross Domestic Product and Deaths, 1910-1930

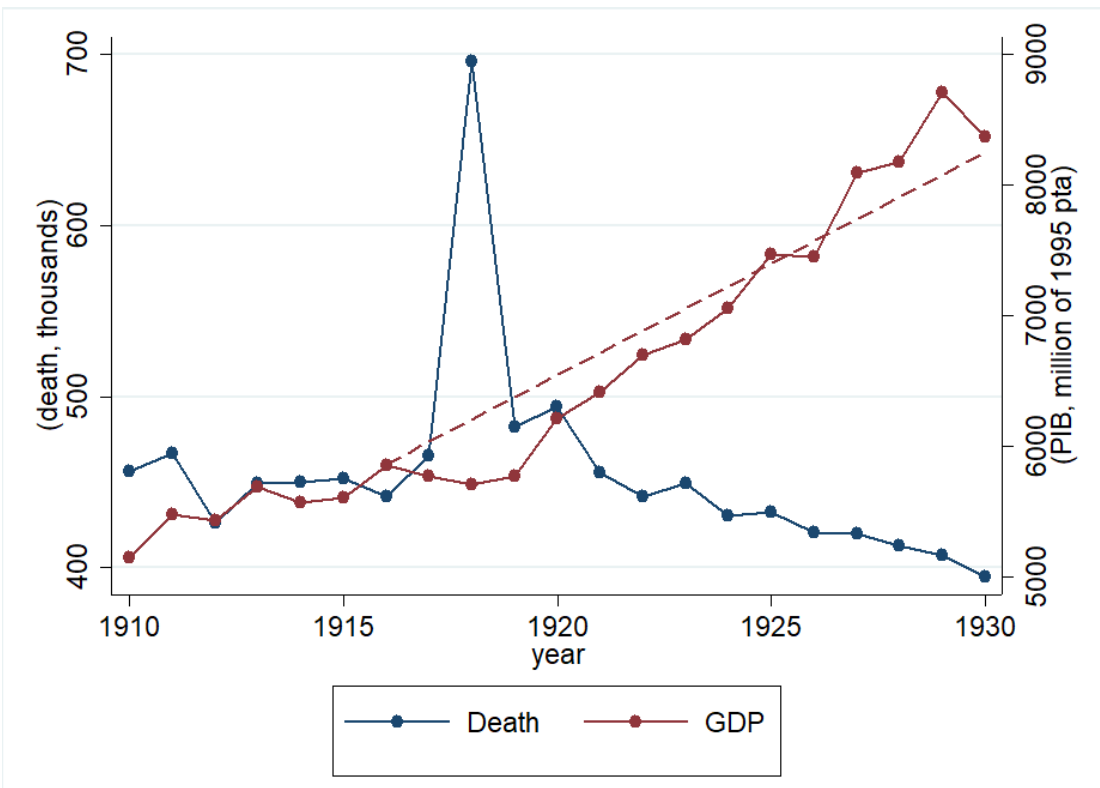

Sources: Death data obtained from INE Base Historica and Gross Domestic Product (GDP) in 1995 constant prices from Prados de la Escosura (2017)

In the early 20th century, Spain was still a developing economy. Using data from the the Maddison project latest release, Gross Domestic Product (GDP) per capita was 62 per cent of UK's and 51 per cent of the US' in 1918 (Bolt et al. (2018)). Industry represented 27 per cent of total output in 1920 and employed slightly less than 20 per cent of the working population (Carreras (2006)). Real GDP increased until 1916 but declined thereafter. 1918 culminated two years of straight falls in total output, with output increasing in 1919 and 1920 and accelerating in the 1920s (Prados de la Escosura and Rosés (2009)). Figure 2 illustrates this evolution of GDP along with the sudden increase in the number of deaths in 1918. GDP reaches a trough in 1918. Note that even though the decline in aggregate GDP in 1918 does not seem large (it is only a 1 percent decline), it represents a substantial deviation from the 1910-1930 trend of 6.45 per cent.

Table 2 reports some aggregate statistics to put 1918 into perspective. The numbers in the table represent percentage deviations from the 1910-1930 linear trend. As we could see in Figure 2, the deviation from the trend of GDP was quite large in 1918. However, we want to emphasize the difference across sectors. Most of the decline is found in the services and industry sectors. The decline in production of the agricultural sector was mild.

Investment was very volatile in the period. Aggregate investment sharply declined in 1918 and its fall was generalized across all types of investment. Building construction represented 70 per cent of all domestic capital formation Prados de la Escosura (2017). There is a contraction 
Table 2: Output and consumption. Percentage deviations with respect to linear trend

\begin{tabular}{|c|c|c|c|c|c|}
\hline Output & GDP & GDPpc & Agricultural & Industry & Services \\
\hline $1915-1917$ & -1.13 & -0.70 & 3.07 & -0.74 & -3.65 \\
\hline 1918 & -6.45 & -5.52 & 2.18 & -7.46 & -9.66 \\
\hline 1919-1930 & -0.97 & -0.69 & 0.04 & -2.56 & -0.61 \\
\hline \multicolumn{6}{|l|}{ Gross Domestic } \\
\hline Fixed Capital & Total & Dwellinos & Other & Machinery & Transport \\
\hline 1915-1917 & -19.02 & -15.71 & -16.9 & -10.47 & -30.71 \\
\hline 1918 & -34.15 & -49.49 & -52.48 & -34.29 & 6.47 \\
\hline 1919-1930 & -6.09 & -3.4 & -12.09 & -3.43 & -5.59 \\
\hline Consumption & Consumption & Food & Textiles & Utilities & Services \\
\hline $1915-1917$ & -7.26 & -3.88 & 8.94 & -2.53 & -8.16 \\
\hline 1918 & -6.11 & 4.11 & -10.34 & 0.73 & -20.48 \\
\hline 1919-1930 & -0.49 & 0.17 & -2.31 & -0.95 & -1.92 \\
\hline
\end{tabular}

of investment in buildings after 1914, meaning the trend in investments in dwellings and related was below trend from 1915 to 1925. In 1918, new dwellings were 34 per cent below trend. Investment in machinery and equipment also collapsed after 1913, and was 34 per cent below trend in 1918. Representing between 10 and 20 per cent of total investment, investment in transport was 31 per cent below trend in 1915-1917, but was the only class of investment above trend in 1918.

Consumption was affected by accelerating prices, changes in relative prices and finally the pandemic. Real consumption slightly increased in 1918, with respect to 1915-1917 average. However, this aggregate number masks substantial heterogeneity across sectors. The consumption of textiles significantly decreased in 1918, it was 10.3 per cent below trend. Consumption of services was 20.5 per cent below trend in 1918. This is in stark contrast with food consumption, which was 4 per cent above trend in 1918. This heterogeneity in consumption suggests that demand for not-necessary goods (like textiles) significantly declined in 1918. The pattern of consumption in textiles and services seems to confirm this idea. We want to note that consumption in this four items comprises around 90 percent of total consumption (Prados de la Escosura (2017)).

To conclude, the Spanish Flu reached Spain in a moment in which it was transitioning towards a developed economy. The aggregate data seems to indicate that the decline in production and consumption was heterogeneous across sectors. Given this heterogeneity, controlling for year and taking into account province-specific prices, it is possible that the economic effects of the flu were also heterogeneous across provinces and the distribution of the potential losses 
was different within the provinces. We will empirically analyze these questions in the ensuing sections.

\section{Identification, Empirical Strategy, and Data}

\subsection{Measure of Flu at Province Level}

In the previous section, we have argued that, at the country level, the Spanish Flu did not seem to have a very large effect on the economy. However, this aggregate effect could be masking substantial heterogeneity across provinces. To assess this effect, we need first to obtain a measure of the intensity of the flu at the province level.

We use two measures of the flu. In our first measure, we just compute excess mortality in each province over time, allowing for the flu pandemic to increase mortality in various years and allowing other unnoticed excess mortality episodes to have effects on our variables of interest. Our second measure is excess mortality only in 1918, which is the year with the greatest mortality. This measure will allow us to assess the effect of the Spanish flu over time and its potential persistence.

Figure 3 reports the evolution of "excess mortality rate" measure for the different provinces. As it can be seen from the figure, this variable is mostly zero for all years, except in 1918 when there is a peak. This peak in 1918, the "Flu", is clearly noticeable across provinces. Figure 4 plots the geographical distribution of "excess death rates" in 1918 across provinces. We want to emphasize that there is substantial heterogeneity across provinces. In particular, the average value of the "Flu" is 12.6 per thousand people and the standard deviation is 4 per thousand. We will exploit this within-country variation in our empirical exercise. In a addition, it does not seem that "excess death rates" are positively correlated to population or urbanization. Indeed, large populated and urbanized provinces like Barcelona and Madrid belong to the group of less affected provinces. We will use this heterogeneity to discuss the relative importance of the supply and demand-driven interpretation.

\subsection{Empirical Strategy}

We start by analyzing the short-run effect of mortality fluctuations on our outcomes of interest. In this equation, most of the effect is absorbed by deviations from trend in 1918 and 1919, but we let any deviation of mortality from the province-specific trends to affect our outcomes of interest. This specification does not allow for persistence effects of large pandemics, mortality changes shift the market equilibrium in the short run, and markets bounce back to their original equilibrium once mortality goes back to its trend.

$$
\mathrm{Y}_{c t}=\beta * \text { Deviation Mortality }_{c t}+\delta_{c}+\delta_{t}+\epsilon_{c t} \text {, }
$$


Figure 3: Excess Mortality, 1910-1930

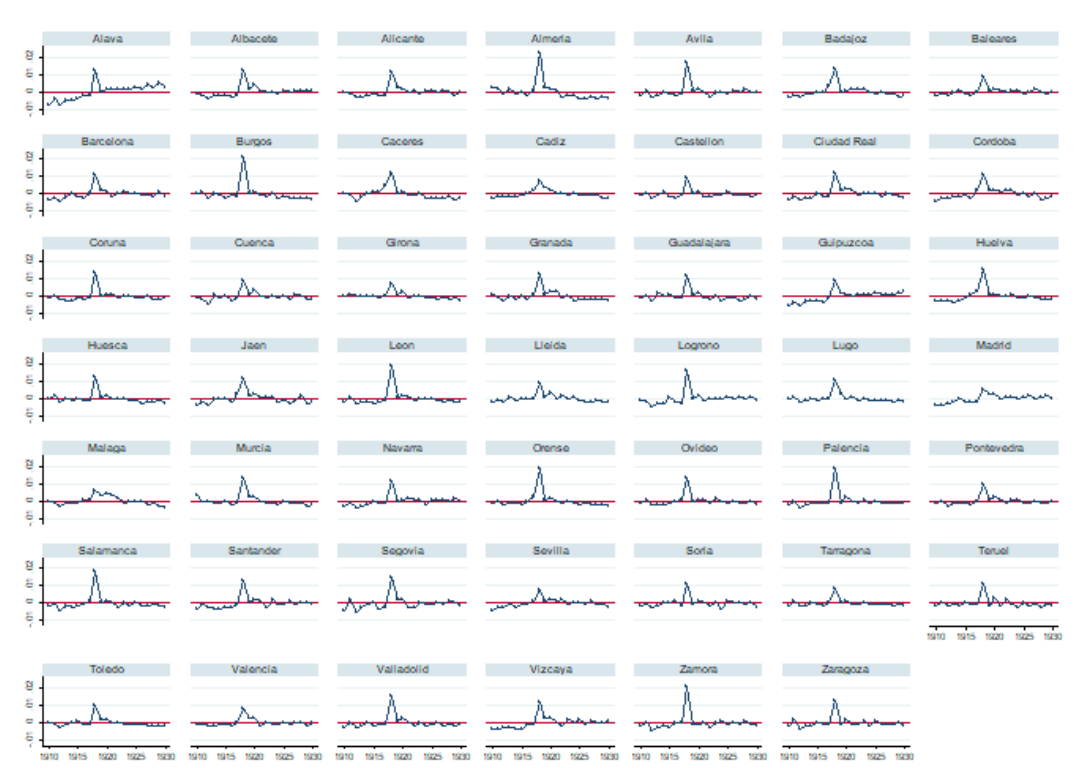

Notes: Excess death rate obtained as deviation from the predicted linear trend (normalized by population), by province. Death data obtained from INE Base Histórica and Census Data.

Figure 4: The Flu: Excess Mortality Rate in 1918

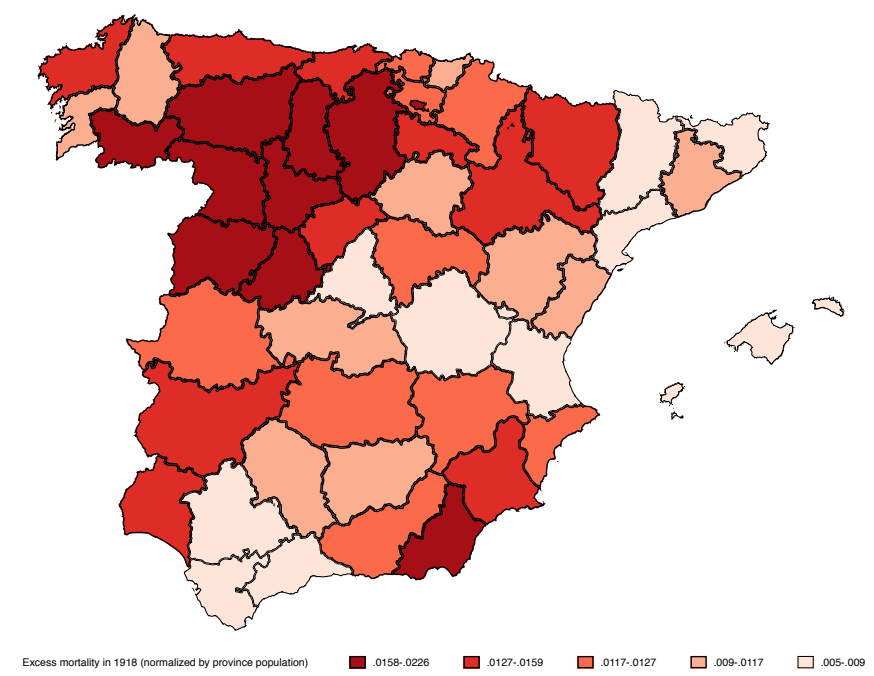

Notes: The map represents excess mortality rate in 1918. Excess death rate obtained as deviation from the predicted linear trend (normalized by population), by province. Death data obtained from INE Base Histórica and Census Data. 
where $Y_{c t}$ is the annual growth rate of the outcome variable for province $c$ and year $t$, following the main specifications in Barro et al. (2020). Deviation Mortality $y_{c t}$ is the difference between actual number of deaths and predicted (normalized by population size) for province $c$ at year $t$, and $\delta_{c}$ and $\delta_{t}$ are province and year fixed effects, respectively. The variable of interest is $\beta$. Indeed, $\beta<0$ implies that a one percent increase in the excess death rate, decreases the outcome variable by $\beta$ percent. In this specification, the effect is symmetric on both sides of the trend: the size of the effect of a province having below or above mortality with respect to the province linear trend should be of the same size (and different sign).

Targeting specifically the impact of the pandemic and allowing for the persistence of effects, we run differences-in-differences equations in which provinces vary by the intensity of the flu pandemic in 1918 only. In this equation, mortality deviations from trend in each year before and after 1918 do not matter and it is only the effect of the mortality deviations in 1918 that has effects in 1918 and later,

$$
\mathrm{Y}_{c t}=\beta_{t} * \sum_{t=t_{1}}^{T} \mathrm{Flu}_{c} * \mathrm{D}_{t}+\delta_{c}+\delta_{t}+\epsilon_{c t}
$$

where $F l u_{c}$ is the excess mortality rate in 1918 in province $c, D_{t}$ is a dummy equal to one for period $t$ and zero otherwise. As in the above specification, $\delta_{c} \delta_{t}$ are province and year fixed effects, respectively. The sample is between 1915 and 1930. In our baseline regressions, we consider two periods affected by the pandemic, 1918 and post-1918. The omitted variable is the pre-1918 period. That is, $\beta_{t}$ should be interpreted as the change in the outcome variable relative to the pre-1918 mean of the outcome variable. We want to separate the effect at impact and afterwards to have a sense of the relative persistence of the shock. In addition, to gauge the speed of the potential recovery, we disentangle the post-1918 effect by adding more time dummy interactions. Finally, as an additional robustness check on the potential persistence effect, we will interact $F l u_{c}$ with post-191\%.

Finally, as an extension, we also look at the heterogeneous effects of excess mortality as a function of the population density and industrialization share. In order to do that, we include interactions with population density and share of the population in the industry sector, respectively.

\subsection{Data}

We obtain our data from different official sources. Data on the number of deaths, disaggregated by provinces over time, are obtained from the Historical Database of the Spanish National Institute (INE Base Histórica). Table 3 reports the average and the standard deviation for the three sub-periods of interest. As it can be seen, the average number of deaths is quite similar both before and after 1918. However, as expected, the average number of deaths increased substantially in 1918. One interesting feature is that the standard deviation in 1918 is much 
higher than in any of the other two sub-periods. This higher standard deviation implies that the increase in the number of deaths was very heterogeneous across provinces.

The analysis on the effect of the flu on real wages will be the core of our paper. We have data on annual real wages for 9 different occupations at the province level between 1915 and 1930 (computed using prices and nominal wages for several occupations in the capitals of each province). We obtain these data from Spain's annual statistical yearbook. The occupations groups are workers in agriculture sector, builders, stone-cutters, carpenters, blacksmiths, workers in metal sector, painters, tailors and shoemakers. These occupations comprised a large share of workers at the time and they also cover industries with different degrees of tradeability and skill-intensity. Actually, around 50 percent of the Spanish population was employed in the agricultural sector ( Prados de la Escosura (2017)). Nonetheless, there was substantial heterogeneity on the levels of industrialization across provinces (see Table 12). As it can be see from Table 3, for most occupations, the real wage in 1918 was below the pre-1918 average. From this average values, it would seem that workers were negative affected by the Spanish Flu. However, we need to formally test this effect. In addition, at first sight, we do not observe significant differences across occupations, but we will examine this potential heterogeneous effect in the next section.

We are also interested in the effect of the flu on the returns of capital. This is a more difficult exercise because we do not have, at the province level, data on returns to capital. However, we have two proxies for these returns. On the one hand, we use data on dividends from the Estadística de Utilidades which provide information on dividends paid by public companies Tafunell (2000). ${ }^{2}$ A noticeable fact from Table 3 is that the average value of dividends was substantially larger in 1918 than the previous sub-period. Moreover, this larger average comes in hand with an also substantially larger standard deviation. Once again it hints to a potential heterogeneous effect across provinces. We will exploit deviations from general year effects in the evolution of dividends to analyze the impact of the flu on returns to capital.

Our second proxy for returns on capital are real estate prices. In particular, urban housing prices and rural land prices. Both prices have been deflated with a provincial cost-of-living index. We obtain data on real average house prices and real land prices at the province level from Carmona and Rosés (2012) and Carmona et al. (2017, 2019). From Table 3, we want to emphasize two features. First, the value of average real prices in 1918 was higher than the previous period. Second, there is a substantial increase in the variation across provinces, especially in housing prices. One shortcoming of using the average price of each year's sales is that there may be a selection problem in the type of houses being sold. This problem may be more serious in 1918 as fewer housing units were sold. Thus, we must take these concerns under consideration on our analysis.

\footnotetext{
${ }^{2}$ Data by province-year have been kindly provided by Miguel Artola
} 
Table 3: Summary Statistics

\begin{tabular}{lllllll}
\hline Variable & $\begin{array}{l}1915-1917 \\
\text { Average }\end{array}$ & St.Dev. & $\begin{array}{l}1918 \\
\text { Average }\end{array}$ & St.Dev. & $\begin{array}{l}\text { Post-1918 } \\
\text { Average }\end{array}$ & St. Dev. \\
\hline Deaths & 9252 & 4884 & 14199 & 6970 & 9292 & 5194 \\
& & & & & & \\
Wages: & & & & & & \\
- Agriculture & 1.87 & 0.44 & 1.97 & 0.62 & 2.84 & 0.94 \\
- Builder & 2.76 & 0.60 & 2.64 & 0.51 & 4.09 & 0.98 \\
- Stone-cutter & 3.00 & 0.68 & 2.90 & 0.58 & 4.25 & 1.03 \\
- Carpenter & 2.79 & 0.59 & 2.62 & 0.66 & 4.01 & 0.95 \\
- Blacksmith & 2.76 & 0.73 & 2.55 & 0.61 & 3.68 & 0.90 \\
- Metals & 2.84 & 1.23 & 2.67 & 1.11 & 3.93 & 1.80 \\
- Painter & 2.70 & 0.65 & 2.55 & 0.57 & 3.89 & 1.01 \\
- Tailor & 2.63 & 0.83 & 2.40 & 0.84 & 3.49 & 1.12 \\
- Shoemaker & 2.40 & 0.64 & 2.25 & 0.64 & 3.33 & 0.94 \\
& & & & & & \\
Dividends & 6551 & 22033 & 9869 & 32300 & 9939 & 31100 \\
& & & & & & \\
Real estate prices: & & & & & & \\
- Urban housing & 4633 & 7510 & 6888 & 12254 & 8822 & 16551 \\
- Land prices & 1485 & 1416 & 1964 & 1993 & 2759 & 3012 \\
& & & & & & \\
\hline
\end{tabular}

Notes: Death is number of deaths for province and year from INE Historical Database. Wages are average real wages for province and data from Rosés and Sánchez-Alonso (2004). Dividends are thousands of pesetas from from the Estadistica de Utilidades. Number of taxpayer firms in the industrial sector are in thousands. House prices are the ratio of value of all transactions (in pesetas) over the number of transactions. Land prices and urban data obtained from Carmona et al. (2014). All post-1918 are 1919-1930, except for dividends which the series stops in 1919 and number of taxpayer firms, which the series stops in 1925. 


\section{The Effects of the Flu on the Returns of Factors}

This section presents the main results of the paper. We examine how the economic effects of the flu are shared within the country. The core of the paper is the analysis of the effect of the flu on real wages. Then, we also examine the effect on our two proxies of returns to capital (dividends and real estate prices). We will also examine how these effects differ across provinces.

\subsection{The Effect of the Flu on Real Wages}

We start by looking at the impact of mortality changes on real wages. Equation 1 assumes factor markets flexibly adjust and recover from shocks. Theoretically, it is not clear which should be the effect of excess mortality on real wages. On the one hand, a decline in labor supply should tend to increase real wages because, given demand, there is less competition for the job. On the other hand, a deterioration of general health conditions, social distancing and uncertainty, can be conducive to an overall decline in demand and, thus, a fall in real wages. It is outside the scope of this paper to disentangle both effects. We are only interested in empirically examining the overall effect of the flu on real wages.

Table 4 reports the effect of deviations from mortality rate trends on the annual growth rate of real wages for nine occupations. We have annual data for all provinces between 1915 and 1930. Panel A reports the coefficients of running equation 1. Remember that, in this specification, we include province fixed and year fixed effects. The first thing to notice is that the coefficient of mortality is negative for all occupations, meaning increases in mortality from trend reduce real wages and decreases in mortality increase them. Moreover, the estimated coefficients are quite large. All coefficients are statistically significant, except in the case of agricultural and metal workers. The coefficient for stone-cutters is significant at 10 percent. Therefore, there exists substantial heterogeneity across occupations.

The size of coefficients means that there were large effects of mortality increases on real wages. For example, the average increase in mortality relative to trend in 1918 was 12.6 per thousand people, which according to our coefficient would translate in a reduction of real wages that ranged from 15 and 13 per cent in the case of shoemakers and tailors to null effect for agricultural workers. For most occupations, the effect is between 9 and 10 per cent. The highest mortality deviation in 1918 was 2.26 percent, meaning excess mortality reduced wages by around 25 per cent in 1918 in the most affected province. The lowest deviation from the province-specific mortality rate trend in 1918 is 0.5 percent, which would decrease wages by about 5 per cent for tailors. Because the largest deviations in mortality trends happened in 1918, it is highly probable that 1918 alone explains most of the negative coefficient. The yearfixed effect of 1918 is positive and significant in all categories, but excess mortality in 1918 dampened the general improvement in real wages.

In order to allow for a delayed recovery from the shock, we include the lag of the mortality 
deviation in our regression. If the shock were temporary, we would expect that the coefficient of the lag of the mortality deviation had the opposite effect of the contemporaneous effect. This exercise is reported in Panel B of Table 4. The coefficient of the lag of mortality deviations is generally positive, but it is not statistically different from zero. Actually, the only coefficients statistically different from zero, at 10 percent, are the coefficient on blacksmiths, which is negative (column 4) and shoemakers, which is positive (column 9). The fact that the coefficients on the lag are generally not statistically different from zero would seem to imply that the effects of mortality deviations were persistent. However, this interpretation would be wrong. Indeed, we need to test whether the sum of the two coefficients, labelled as "total effect", is different from zero. When we do that, we see that the coefficients of "total effect" are negative but they are not statistically different from zero. The only two exceptions are blacksmiths and builders. For these two occupations, the effects of mortality deviations linger for more than a year.

Panel C in Table 4 reports the coefficients of running equation 2. The main coefficient measures the impact of the intensity of the influenza (proxied by the deviation from the provincespecific trend in 1918) both in the short- and medium-run. In this accounting exercise, we compute the differential effect of "excess mortality" in 1918 on the evolution of real wages growth across provinces. The dependant variable and the fixed effects are the same as in the previous panels. We include separate interactions for 1918 and post-1918 because, as shown above, mortality deviations do not seem to have had persistent effects and if we only had a post-1917 dummy, it would mask the contemporaneous effect of the flu on wages (we do this exercise in Panel D). First, we focus on the interaction between "excess death rate" in 1918, labelled as "Flu 1918" and the dummy for 1918. Note that the coefficient is negative and statistically different from zero for all occupations, except for metal workers. The coefficient ranges between -5.2 for metal workers to -27.8 for shoemakers. The average "excess death rate" in 1918 was, according to our data, 1.26 percent. Thus, quantitatively, these coefficient imply that the the flu reduced real wages from 6.7 percent (metal workers) to 35 percent (shoemakers). For agricultural workers, the coefficient implies a decline of 21 percent. This evidence confirms the findings reported in the previous panel that the Spanish Flu had large contemporaneous effects on real wages. We want to emphasize that the largest coefficients are for shoemakers and tailors, which hint towards a demand-driven interpretation.

To assess the persistence of the shock, we can look at the interaction between "excess death rate" in 1918 and the post-1918 dummy. Figure 5 reports the coefficients of the interactions of Flu 1918 and the time dummies. If the flu had no persistent effects, we would expect that the coefficient for post-1918 period to be positive. If we look at the coefficients in the figures, it does seem that after the drop in 1918, the coefficients tend to recover. However, the coefficients of the post-1918 are generally negative (even though they are not statistically different from zero at conventional levels). The notable exceptions are tailors and shoemakers, whose coefficients for post-1918 are also negative and statistically significant. In order to test the persistence of the 
Figure 5: Effect of Spanish Flu on Real Wages (by Occupation)

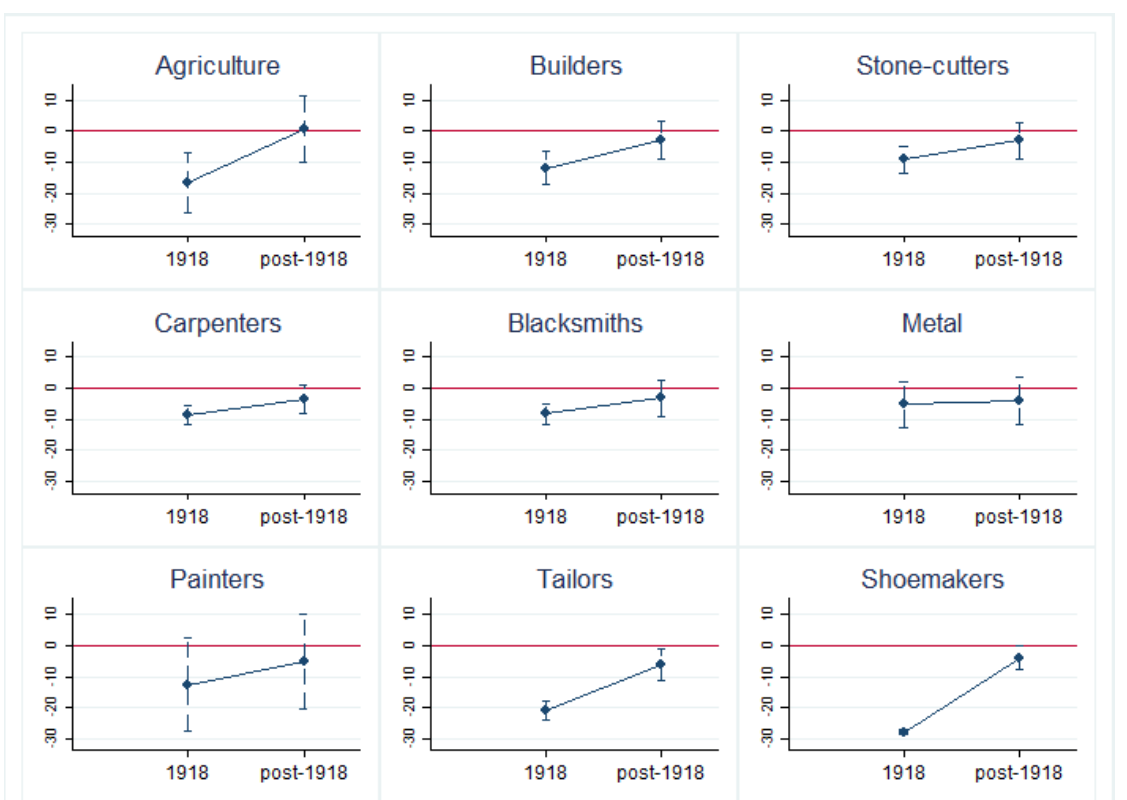

Notes: Each point is the coefficient of the interaction between "excess death rate" in 1918 and the time dummies. The dashed line is the 95 percent confidence interval. Pre-1918 was excluded from the regression and it is the reference group. The coefficients are reported in Table 4.

effect, we cannot just test whether the sum of these coefficients is different from zero because the post-1918 variable is an average of more than just one year (up to 1930). We formally test the persistence of the shock in Panel D. In this panel, we run the same type of diff-in-diff regression of Panel C(equation 2), however, we only include the interaction between the Flu and post-1917 dummy. If this coefficient were negative, it would imply that provinces with a higher "excess death rate" had persistently lower wages after 1917. We note that this interaction is generally negative but it is not generally statistically different from zero. The notables exceptions are, once again, the coefficients for tailors and shoemakers with are negative and statistically significant, which hints to persistent effects of the flu for these two occupations. We conclude that the effect of the Spanish Flu was intense but temporary for most occupations. One possible interpretation is that real wages would have increased in absence of the flu in 1918, but the flu depressed real wages in 1918. This might explain the vast social explosion of 1919. It is important to note that in the inflationary context of the 1910s, there was no need for employers to cut nominal wages. In this case, just having upward stickier nominal wages would be enough, as inflation would erode the purchasing power of workers. In areas with greater flu intensity, perhaps employers resisted nominal wage increases. We plan to further investigate this channel in future research.

Finally, to assess the shape of the recovery, we disentangle the post-1918 coefficient in Panel C. Remember that in this specification, the interaction with pre-1918 dummy is excluded 
from the regression and it is the control group. This is a very demanding regression because we interact Flu with several year dummies. Figure 6 plots these coefficients for all nine occupations. Consistent with the previous evidence, the main negative effect of the flu on real wages is in 1918 and it then tends to recover over time, especially around 1921-22, when we observe some positive coefficients, meaning faster than average recovery in provinces particularly affected by the flu. However, as we argued before, there is a lot of heterogeneity across occupations. Agricultural workers, stone-cutters and blacksmiths are the first to experience some gains, whereas tailors and shoemakers, with the exception of the rebound in 1919, seem to remain below pre-1918 levels throughout the period.

We can conclude from this exercise that the Spanish Flu had large but, in general, shortlived effects on real wage growth. Moreover, the effects on real wages were heterogeneous across occupations. The fact that the negative effect on real wages was widespread and relatively larger in occupations like tailors and shoemakers lends support to a demand-driven interpretation. Arguably, the uncertainty and social distance started to reduce consumption earlier than the peak in the number of deaths, specially among non-essential goods like shoes or dresses. The aggregate data documented in Table 2 also hints to this differential effect on consumption. A test of this channel is outside the scope of the paper. We provide suggestive evidence on this demand-driven hypothesis by comparing the effects of the flu across provinces. To formally test this hypothesis, we would need firm data, which is not currently available, and we leave it for future research.

Robustness These results are robust to alterations of the main specification and sample splits. First, one possible concern is that the presence of outliers in "excess mortality" drives our results. To address this concern, we winsorise our measures of mortality rates and flu in 1918. Table 5 shows that the results do not change qualitatively when we perform this exercise. Then, another potential concern is that the effects are driven by relatively small provinces and, thus, they are not quantitatively relevant. To address this concern, we perform weighted regression with population weights. Table 6 shows that the coefficients are roughly the same, albeit somewhat larger. A related potential concern is that the results may be driven by two of the richest and more urbanized provinces (Barcelona and Madrid, see Table 12). Table 7 reproduces the results without these provinces. Once again, the qualitative results are almost identical. In the next section, we formally explore this potential heterogeneity in the effects on real wages. Finally, one last concern is the potential existence of spatial autoregressive errors. To address this concern, we use a modified real wage that controls for spatial autocorrelation (Getis and Ord (1992)), which has been used in Carmona and Rosés (2012). Table 8 reproduces the results when using this alternative measure of real wages. We note that both the qualitative and quantitative results are very similar. 
Figure 6: Dynamic Effect of Spanish Flu on Real Wages Over Time
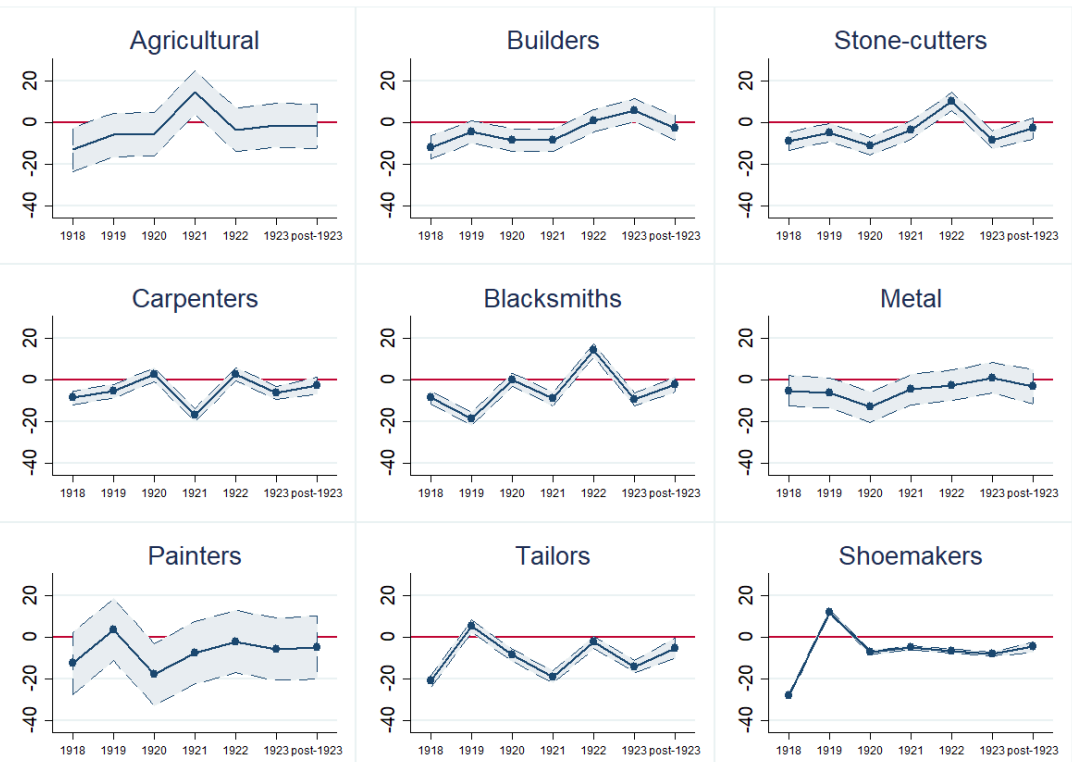

Notes: Each point in line is the coefficient of running the interaction between "excess death" in 1918 on different time dummies. The area represents the 95 percent confidence interval.

\subsubsection{Heterogeneous Effects Across Provinces}

Spain in early twentieth century was a very heterogeneous country, Table 12 reports some province characteristics in 1910. We focus on the share of the working population employed in industry and population density. Even though the two variables are correlated, they proxy different variables. We use the share of the population employed in the industry as an index of industrialization. The population density is our proxy for urbanization.

Population Density Denser provinces concentrated more deaths in 1918 but had lower mortality rates. Indeed, the pairwise correlation between population density in 1910 and excess mortality in 1918 (normalized by population in the province) is negative and statistically significant. For instance, the "excess death rate" in 1918 was 1.12 percent in Barcelona (one of the most densely populated provinces), while it was 1.93 in León (one of the least densely populated) (see Table 12). Arguably, the spread of news on the Spanish Flu was larger in more urbanized provinces, where the access to newspapers was more widespread. Thus, one potential reason for this difference in death rate across provinces is that people in provinces with more population density were more aware of the dangers of the flu and followed social distance measures. Following this argument, we would expect that the reduction in non-essential goods was exacerbated in provinces with larger population density. If this demand-driven interpretation is correct, we should find that the negative effects of the flu on real wages are exacerbated in provinces with more population density. 
Panel A examines this potential exacerbation effect of the flu on real wages. In particular, we include in our baseline regression 1 the interaction between "excess mortality rate" and population density dummy. This variable is equal to one if the population density is above the median of the distribution 1919. Note that we still include province and year fixed effects. We find that the coefficient of the interaction term is negative and statistically significant. The only exception to this general is the positive effect on stone-cutters. The exacerbation effect is specially large for tailors, shoemakers and blacksmiths. Quantitatively, for example, for tailors, one percent increase in "excess death rate" results in a decline of real wages of 7 percent in a province below the median of the population density distribution. In contrast, in a province with a population density above the median, the effect of one percent increase represents a decline of 19 percent of real wages. This exacerbation effect and the fact that it is biased towards tailors and shoemakers is consistent with our demand-driven interpretation. In other words, it seems that reduction in consumption more than deaths explains the fall in real wages.

These results are robust to alternative measures of urbanization. Table 10 reports the coefficients of the interaction with an urbanization measure based on the share of the population in the province living in municipalities of more than 25,000 inhabitants. Note that the sign and qualitative results are roughly the same (Panel A). The exception is that the coefficient of tailors is negative but it is not statistically significant. One possibility is that these measure of urbanization may fail to fully capture the impact on aggregate demand of the province. In Panel B we make use of our population density measure to reclassify five provinces, which are potential outliers and, thus, they may distort our results. In particular, Badajoz, Zaragoza and Córdoba are reclassified as non-urbanized given their low population density and mostly rural population. Similarly, Pontevedra and Orense are reclassified as urbanized given their large population density. If we compare both panels, we observe that most of the coefficients are roughly the same. The only significant change is that the effect on both tailors and shoemakers is exacerbated and quantitatively larger. Thus, the overall evidence reported in Table 9 and Table 10 paints a picture consistent with our demand-driven interpretation.

Industrialization The levels of industrialization were very heterogeneous in Spain. Industrialization is correlated with level of development and industrial establishments also crowded people together facilitating the spread of the pandemic. In a supply-driven interpretation, the effects of the flu should be mitigated in more industrialized provinces. That is, given the same increase in excess death rate, the decline in job competition should be exacerbated in more industrialized provinces. In a demand-driven interpretation, the sign would tend to be negative because, arguably, the decline in demand should be larger in more industrialized and more developed provinces. As an imperfect measure of industrialization, we use the share of the population working in the industry sector in 1910, when the latest Census before the Spanish Flu was made. As we can see from Table 12, there is a lot of heterogeneity across provinces. We also note that this measure of industrialization is correlated with our measure of urbanization, but 
they seem to proxy for different province characteristics. For example, it is true that Barcelona was a very urbanized and industrial province. However, Madrid was a very urbanized province but with a relatively smaller industrial sector. On the other extreme, we have a province like Girona with a relatively larger industrial sector but not very densely populated. That is, even though industrialization may also capture some elements of urbanization, it should allow us to indirectly test our demand-driven interpretation.

Panel B analyzes this potential exacerbation effect of the flu on real wages. Following the same strategy as in Panel A, we include the interaction between "excess death rate" and industrialization level. The coefficient of the interaction term is generally not statistically significant from zero. The only exception is the coefficient for blacksmiths, metal workers and tailors. For the first two, the coefficient is negative and statistically significant, which lends support to our demand-driven interpretation. Quantitatively, for blacksmiths, one percent increase in "excess death rate" reduces real wages 7 percent in a province with industrialization levels below the median. In contrast, in a province above the median, the reduction would be 12 percent. For tailors the interaction term is negative. A possible interpretation is that for this skilled group, the supply effect matters and mitigates the decline in real wages. Note however that the exacerbation effect is much lower than for density (3.78 vs 11.67 in column 8 ), which suggests that the demand effect is quantitatively more important.

The evidence reported in Table 9 is consistent with a demand-driven explanation for the effect of the flu on wages. For a given increase in "excess death rate", the effect on real wages is exacerbated in provinces with a larger population density, where the news on the dangers of the Spanish Flu and, thus, the increase in fear and uncertainty were, arguably, larger. In contrast, the effects on real wages are not positively affected by industrialization levels, which also support the demand-driven interpretation.

\subsection{The Effects of the Flu on Returns to Capital}

We next to turn to the effect of the flu on the return to capital. Since we do not have a series for the return to capital at the province level, we have to use two proxies. First, we examine the evolution of the dividends of publicly listed firms, which proxy the returns of stocks. Because there were only a few stock markets (Madrid, Barcelona and Bilbao), average return on stocks cannot give us the return to owning stocks in each province. For this reason, we use dividends. Then, we look at the evolution of real estate prices (urban housing and land). If the returns to all assets tend to converge, year-to-year changes in housing or land prices should also reflect average returns on capital.

\subsubsection{The Effects of the Flu on Dividends}

Column 1 of Table 11 reports the effects of the flu on dividends paid by public companies. Due to a change in the Spanish law, our last year with comparable data is 1919. Panel A reports 
the baseline regression, equation (1). The coefficient of "excess death rate" is positive but not statistically different from zero. Therefore, it does not seem that an increase in "excess death rate" had any contemporaneous effect on dividends. In Panel B, we include the lag of "excess death". The rationale is that, even though dividends do not have a contemporaneous effect on dividends, it may affect future dividends. This could be the case if the effect of the flu on production is delayed and it accumulated as the death toll increases. We find the coefficient of the lag of "excess death rate" is also positive and statistically insignificant. Panel C and D report the coefficients of the interaction between "excess deaths" in 1918 and time dummies (equation 2). In Panel C, the coefficient on 1918 turns out to be negative and the post-1918 is positive, but none of the coefficients is statistically significant. In addition, if look at Panel D, the coefficient on post-1917 (the medium-run effect of the flu) it is positive, but not statistically significant. Therefore, we conclude that, for the average province, the Spanish Flu did not have any negative effect on dividends paid by public firms. The fact that dividends were not significantly affected by the Spanish Flu seems consistent with the findings of Barro et al. (2020). Indeed, they fail to obtain a significant effect of the flu on real stock returns. Finally, we do not find any significant effect on the potential heterogeneity across provinces. ${ }^{3}$

A potential concern with these findings on dividends is that public firms represent a selected sample of firms. It could be that small and medium firms went bankrupt due to the decrease in demand. Unfortunately, we lack of firm level data to explore this possibility. This is a potential area for future research. In any event, this evidence is consistent with the hypothesis that (public) firms were able to transfer the effect of the drop in demand to workers, while keeping returns to capital unaffected.

\subsubsection{The Effects of the Flu on Real Estate Prices}

To examine the evolution of real estate prices is interesting by itself. There is a general consensus that house prices affect consumption, borrowing, investment and even aggregate productivity (see, for example, Basco (2018)). Moreover, as documented in Jordà et al. (2019), housing is throughout history the largest and most important asset class in the economy. Arguably, this was specially true in early 20th century Spain, in which capital markets were integrated but poorly developed. As documented in Table 3 both urban housing and land prices were, on average, larger in 1918 than in previous years. Moreover, this higher growth went hand in hand with additional variability across provinces. This section analyzes how the Spanish flu affected the evolution of real estate prices. We follow the same strategy as in the previous outcome variables and focus on the variation of annual growth rates to take into account the general increase in prices over the period.

\footnotetext{
${ }^{3}$ We do not report the counterpart of Table 9 for returns to capital for ease of exposition. None of the interactions with population density and urbanization dummies are statistically significant. This table is available upon request.
} 
Theoretically, the effect of "excess mortality" on average real estate prices is ambiguous. First, the income effect should tend to reduce demand and, thus, decrease prices. Second, if the negative income effect is concentrated among low-income workers (as the previous evidence suggests), there may be selection on the type of real estate assets traded, which may result in a higher average price. Third, the supply of available assets may increase because people may be forced to sell, which should tend to decrease prices. To disentangle these effects is beyond the scope of this paper, we will just examine the total effect of "excess mortality" on real estate prices. One additional potential concern is that investors may purchase houses in provinces different from where they live, which could potentially distort the effects of the flu on the return to housing.

Column 2 of Table 11 reports the effects of the flu on urban house prices. Panel A reports the coefficients of running the baseline regression (equation 1). The coefficient of "excess death rate" is negative but it is not statistically different from zero. Thus, it seems that the Spanish Flu did not have a negative contemporaneous effect on house prices. In Panel B, we include the lag of "excess death rate" in our previous specification. We find that none of the coefficients is statistically significant. Actually, the coefficient of the lag is positive. Thus, if anything, the long-run effect of the flu on house prices should be positive. This interpretation is confirmed by looking at Panels $\mathrm{C}$ and $\mathrm{D}$, which report the coefficients of the interaction between "excess death rate" in 1918 and time dummies (equation 2). In Panel C, we see that the coefficient of "excess death" in 1918 is positive for both 1918 and post-1918 dummies, but they are not statistically different from zero. In Panel D, the coefficient for the interaction with post-1917 is positive but, again, it is not statistically significant. Finally, we also fail to find significant heterogeneous effects across provinces.

Lastly, column 3 reports the coefficients of the effects of the flu on land prices. We repeat the same specifications as above. We can see in Panel A that the coefficient is positive but not statistically different from zero. Panel B includes the lag of "excess death rate". In this case, the lag is positive but also not statistically different from zero. Panel C and D report the coefficients of the interaction between "excess death rate" in 1918 and time dummies. In Panel C, we see that the interaction with 1918 dummy is negative and statistically significant. This coefficient is a bit inconsistent with the findings documented in Panel A and B. One concern is that this result may be driven for some small rural province. As a robustness check, column 4 reports the coefficients when performing weighted regressions with population weight. ${ }^{4}$ As we expected, the coefficient of the interaction between "excess death rate" in 1918 and the 1918-dummy is no longer negative nor statistically significant. In addition, the coefficient on Panel D on the interaction with post-1917 dummy is not statistically significant in either of the specifications. Therefore, even though land prices may have declined in 1918 in some rural

\footnotetext{
${ }^{4}$ This concern is not present for dividends or urban housing prices. In any case, we have checked that the results do not qualitatively change when performing weighted regressions by population.
} 
areas more affected by the flu, this does not seem to be a general result. Indeed, we also fail to find that the effect of "excess death" on land prices statistically change in more urbanized or industrialized provinces.

To conclude, the most robust conclusion is that the Spanish Flu did not have a negative effect on real estate prices. Thus, we may conclude that the source of income that absorbed the losses of the Spanish Flu were workers.

\section{Concluding Remarks}

The outburst of Covid-19 cases around the world has greatly increased the interest in the economics effects of pandemics. This paper contributed to this debate by examining the effects of the Spanish Flu (1918) within Spain. In particular, we exploited the variation in excess mortality across provinces to analyze the redistributive effects of the flu. Spain in 1918 was a developing country with half of the population in the agricultural sector. However, Spain was a very heterogeneous country in terms of industrialization and population density, which can help us to forecast the potential economic effects of Covid-19 around the world.

The main contribution of the paper is to document the distributional effects of the Spanish Flu. We found that the effect of "excess deaths" on real wages was large. The fall in real wages was heterogeneous across occupations. For example, occupations like tailors and shoemakers experienced the largest decline, with respect to pre-1918, in real wages (around 25 percent for tailors), whereas some occupations like metal workers were not significantly affected. However, the effects were short-lived and real wages recovered, with the notable exception of tailors and shoemakers. We also showed that the effects were exacerbated in provinces with a relatively high population density. We interpret these results as suggesting that the Spanish Flu represented a negative demand shock and the effects were exacerbated in occupations and provinces where this decline was the largest.

In contrast, we found that "excess death" did not have any significant negative effect on the return to capital. We used two proxies for returns to capital: (i) dividends paid by public companies and (ii) real estate prices (urban housing and land). Dividends were not significantly affected by the increase in the number of deaths. On real estate prices, we also fail to find any significant effect of the flu on changes in urban housing prices or land prices.

Which will be the economic effects of Covid-19? Spain in early 20th is perhaps an example of what could happen in a developing economy in which social distancing is difficult. We do find short-run, intense negative effects of the flu pandemic. These were particularly strong in more urbanized provinces where individuals most probably had higher awareness of the pandemic risks. Denser provinces had lower mortality, but we do find stronger effects of the pandemic intensity differentials, especially on the occupations in non-essential sectors (tailors and shoemakers). According to these results, it seems that most of the effect of the Spanish 
Flu were related to a decline (delay) in non-essential consumption rather than to a decline in production. Moreover, workers absorbed most of the losses, while returns to capital were less affected. For future research, we plan to empirically investigate the mechanism through which workers resulted more affected than entrepreneurs and exacerbated in less urbanized regions. Our hypothesis is that firms reacted to the decline in demand, exacerbated in these regions, by resisting nominal wages increases. 


\section{References}

Acemoglu, D., V. Chernozhukov, I. Werning, and M. D. Whinston (2020): “A Multi-Risk SIR Model with Optimally Targeted Lockdown," Working Paper 27102, National Bureau of Economic Research.

Almond, D. (2006): "Is the 1918 Influenza Pandemic Over? Long-Term Effects of In Utero Influenza Exposure in the Post-1940 U.S. Population," Journal of Political Economy, 114, 672-712.

Anderson, R. M., H. Heesterbeek, D. Klinkenberg, and T. D. Hollingsworth (2020): "How will country-based mitigation measures influence the course of the COVID-19 epidemic?" The Lancet, 395, 931-934.

Baldwin, R. And B. W. Di Mauro (2020): Economics in the Time of COVID-19, CEPR Press.

BArro, R., J. URsúA, AND J. Weng (2020): "The Coronavirus and the Great Influenza Pandemic. Lessons from the "Spanish Flu" for the Coronavirus's Potential Effects on Mortality and Economic Activity," NBER Working Papers 26866, National Bureau of Economic Research, Inc.

Basco, S. (2018): Housing Bubbles, no. 978-3-030-00587-0, Palgrave Macmillan. Springer Books.

Bolt, J., R. InklaAR, H. De Jong, And J. L. van Zanden (2018): “Rebasing 'Maddison': new income comparisons and the shape of long-run economic development," Groningen Growth and Development Centre Research Memorandum 174, University of Groningen.

Brainerd, E. AND M. V. Siegler (2003): "The Economic Effects of the 1918 Influenza Epidemic," Working Paper 3791, Centre for Economic Policy Research.

Carmona, J., M. Lampe, And J. Rosés (2014): "Housing Affordability during the Urban Transition in Spain," Lse working paper.

(2017): "Housing affordability during the urban transition in Spain," The Economic History Review, $70,632-658$.

CARmona, J. And J. R. Rosés (2012): "Land markets and agrarian backwardness (Spain, 1904-1934)," European Review of Economic History, 16, 74-96.

Carmona, J., J. R. Rosés, And J. Simpson (2019): "The question of land access and the Spanish land reform of 1932," The Economic History Review, 72, 669-690.

Carreras, A. (2006): Estadísticas históricas de España, siglos XIX-XX, Fundación BBVA, chap. "Industria".

Chowell, G., A. Erkoreka, C. Viboud, And B. Echeverri-Dávila (2014): "Spatial-temporal excess mortality patterns of the 1918-1919 influenza pandemic in Spain," BMC Infectious Diseases, 14, 371.

Clark, G. (2007): A farewell to Alms, Princeton University Press.

Correia, S., S. Luck, And E. Verner (2020): "Pandemics Depress the Economy, Public Health Interventions Do Not: Evidence from the 1918 Flu," SSR Working Paper 3561560.

Davis, D. R. And D. E. Weinstein (2002): "Bones, Bombs, and Break Points: The Geography of Economic Activity," American Economic Review, 92, 1269-1289.

Galor, O. (2011): Unified growth theory, Princeton University Press.

Getis, A. And J. K. Ord (1992): "The Analysis of Spatial Association by Use of Distance Statistics," Geographical Analysis, 24, 189-206. 
Guerrieri, V., G. Lorenzoni, L. Straub, And I. Werning (2020): "Macroeconomic Implications of COVID-19: Can Negative Supply Shocks Cause Demand Shortages?" NBER Working Papers 26918, National Bureau of Economic Research, Inc.

Hollingsworth, T. D., D. Klinkenberg, H. Heesterbeek, And R. M. Anderson (2011): "Mitigation Strategies for Pandemic Influenza A: Balancing Conflicting Policy Objectives," PLOS Computational Biology, 7, 1-11.

Johnson, N. And J. Mueller (2002): "Updating the Accounts: Global Mortality of the 1918-1920 "Spanish" Influenza Pandemic," Bulletin of the history of medicine, 76, 105-15.

Jordà, , K. Knoll, D. Kuvshinov, M. Schularick, And A. M. Taylor (2019): "The Rate of Return on Everything, 1870-2015," The Quarterly Journal of Economics, 134, 1225-1298.

Jordì, , M. Schularick, And A. M. Taylor (2013): "When Credit Bites Back," Journal of Money, Credit and Banking, 45, 3-28.

(2020a): "Disasters Everywhere: The Costs of Business Cycles Reconsidered," Working Paper 26962, National Bureau of Economic Research.

Jordì, , S. R. Singh, And A. M. TAYlor (2020b): "Longer-run Economic Consequences of Pandemics," NBER Working Papers 26934, National Bureau of Economic Research, Inc.

Lin, Z. And C. M. Meissner (2020): "Health vs. Wealth? Public Health Policies and the Economy During Covid-19," Working Paper 27099, National Bureau of Economic Research.

Maluquer de Motes, J. And M. Llonch (2006): Estadísticas históricas de España, siglos XIX-XX, Fundación BBVA, chap. "Trabajo y relaciones laborales".

Miguel, E. And G. Roland (2011): "The long-run impact of bombing Vietnam," Journal of Development Economics, 96, $1-15$.

Prados De LA Escosura, L. (2017): Spanish Economic Growth, 1850-2015, no. 978-3-319-58042-5 in Palgrave Studies in Economic History, Palgrave Macmillan.

Prados de la Escosura, L. And J. R. Rosés (2009): "The Sources of Long-Run Growth in Spain, 1850-2000," The Journal of Economic History, 69, 1063-1091.

Prados de la Escosura, L. And J. R. Rosés (2010): "Capital Accumulation in the Long-Run: the Case of Spain, 1850-2000," Research in Economic History, 27, 141-200.

Reinhart, C. M. And K. S. Rogoff (2009): This Time Is Different: Eight Centuries of Financial Folly, no. 8973 in Economics Books, Princeton University Press.

Romer, P. M. (1990): "Endogenous Technological Change," Journal of Political Economy, 98, 71-102.

Rosés, J. R. AND B. SÁnChez-Alonso (2004): "Regional wage convergence in Spain 1850-1930," Explorations in Economic History, 41, $404-425$.

Rosés, J. R., J. Martínez-Galarraga, And D. A. Tirado (2010): "The upswing of regional income inequality in Spain (1860-1930)," Explorations in Economic History, 47, $244-257$.

Scheidel, W. (2017): The Great Leveler: Violence and the History of Inequality from the Stone Age to the Twenty-First Century, Princeton University Press.

TAFunell, X. (2000): "La rentabilidad financiera de la empresa española, 1880-1981: una estimación en perspectiva sectorial," Revista de Historia Industrial, 18, 71-112. 
Trilla, Antoni, T. G. And C. Daer (2008): "The 1918 "Spanish Flu" in Spain," Clinical Infectious Diseases, 47, 668-673.

Velde, F. R. (2020): "What Happened to the US Economy During the 1918 Influenza Pandemic? A View Through High-Frequency Data," Working Paper 11, Federal Reserve Bank of Chicago.

VONYÓ, T. (2012): "The bombing of Germany: the economic geography of war-induced dislocation in West German industry," European Review of Economic History, 16, 97-118. 
A Tables 


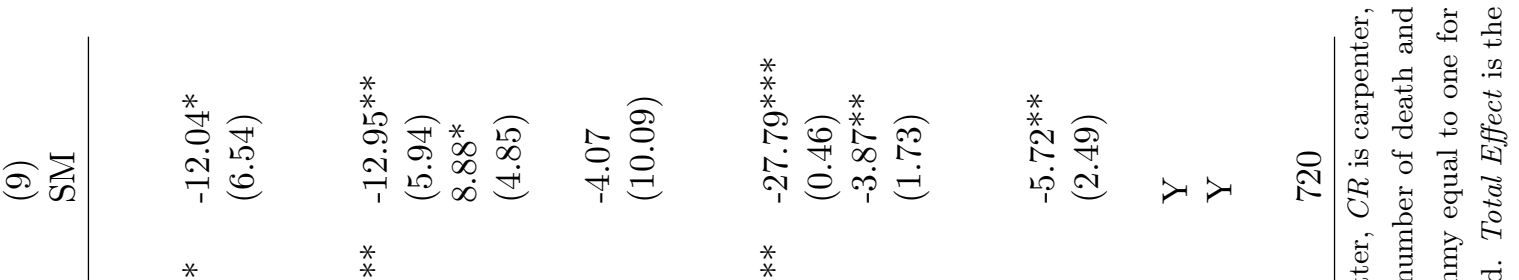

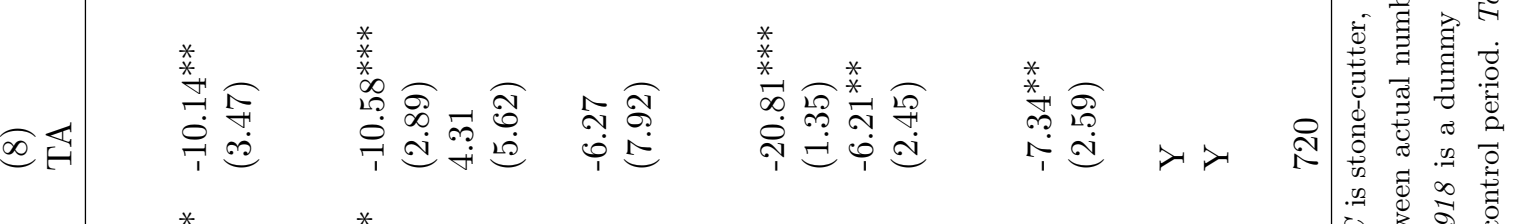

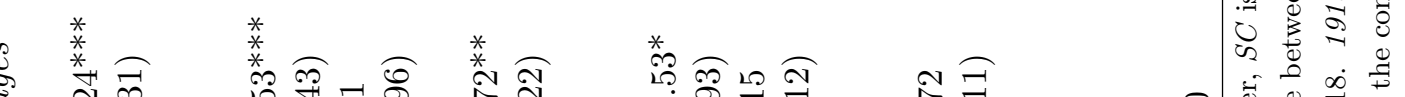

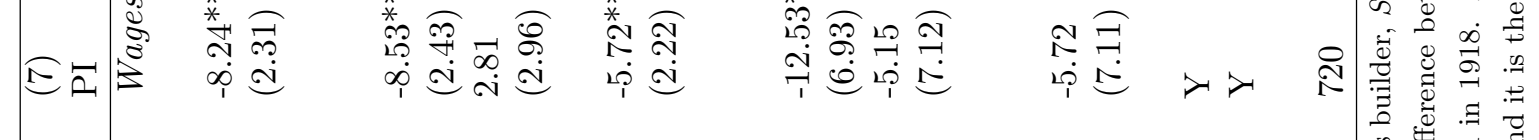

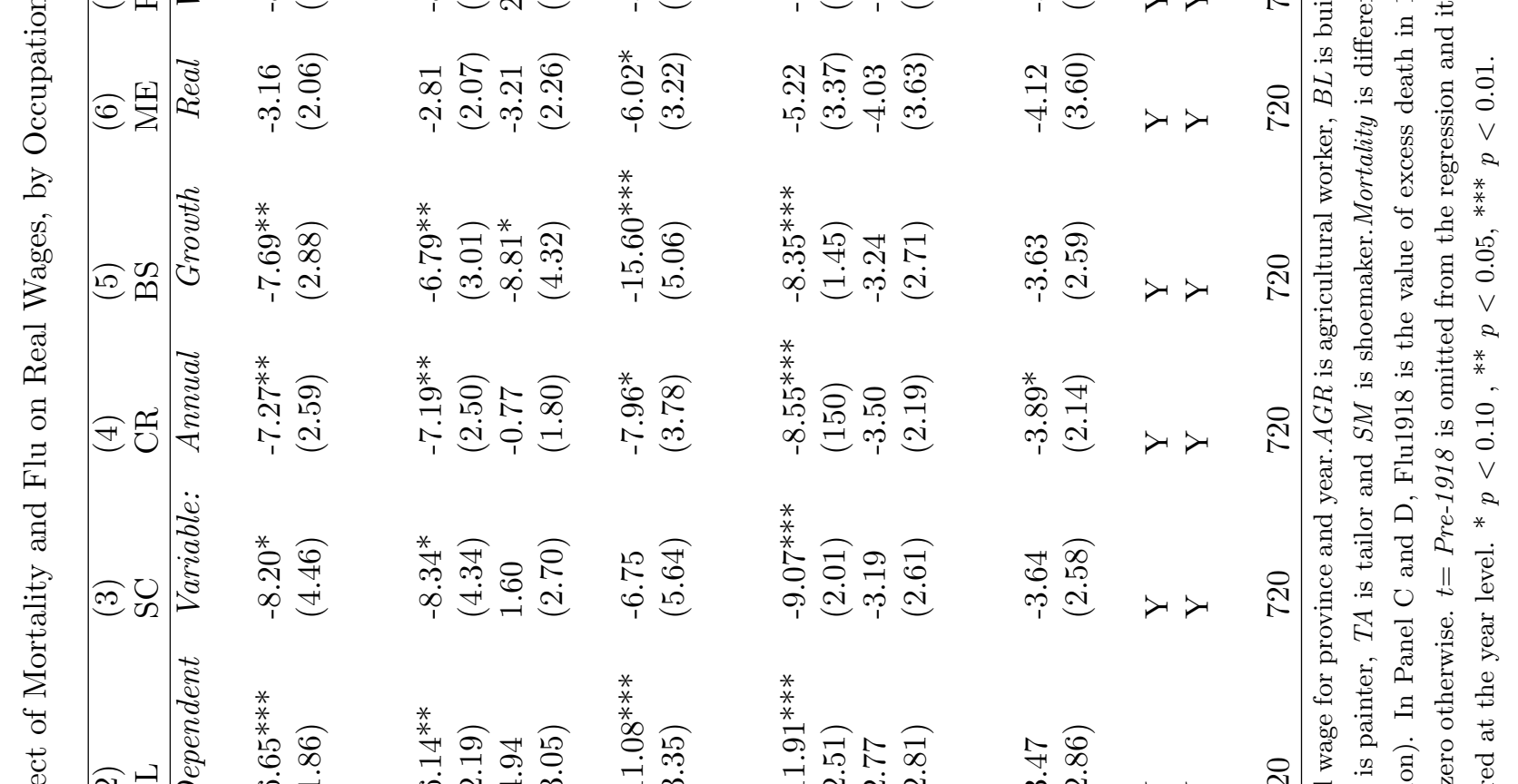

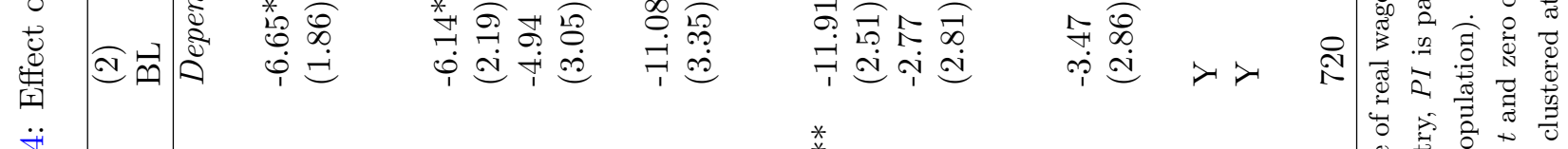

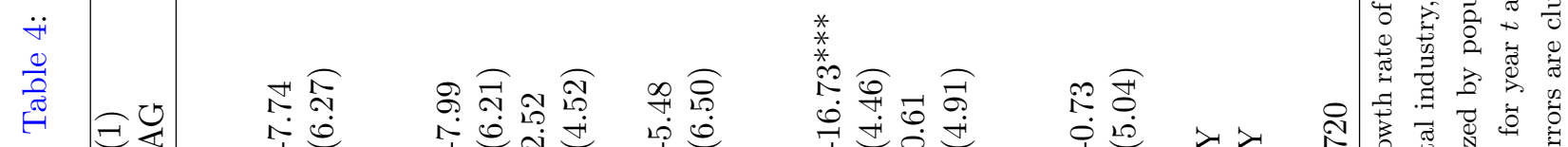

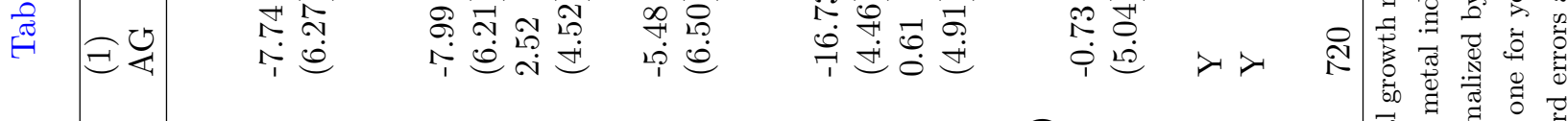

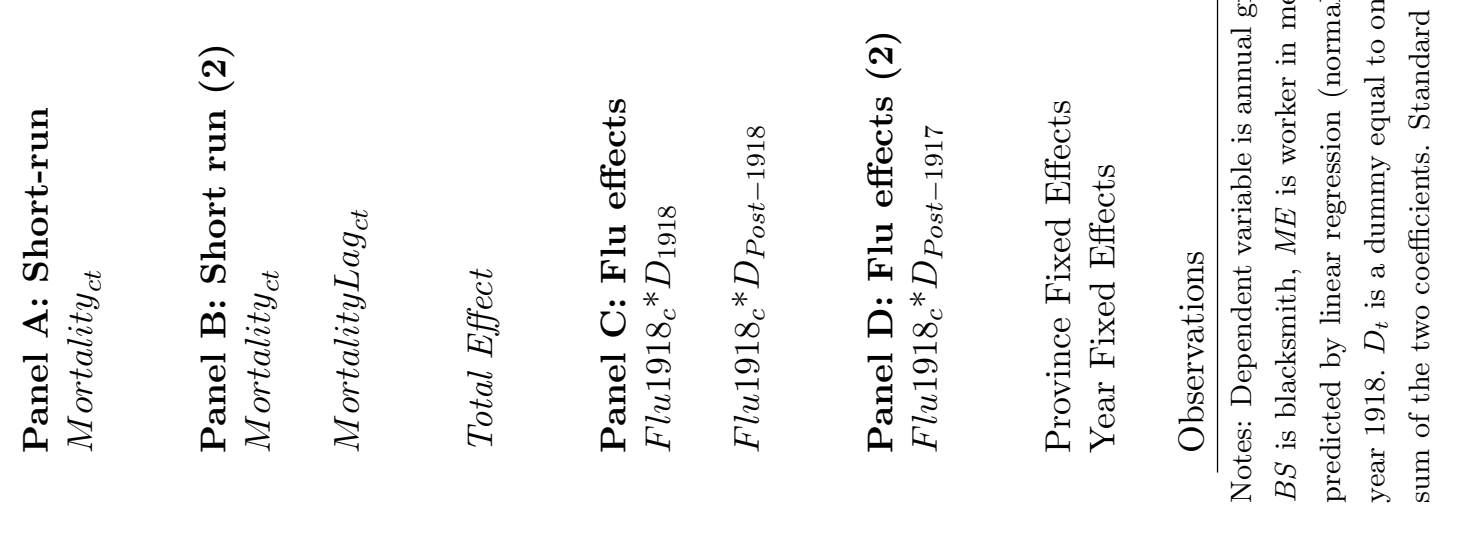




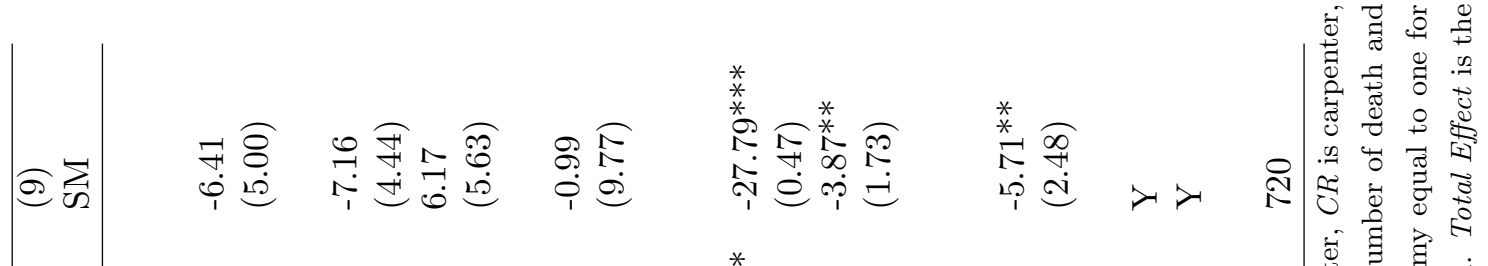

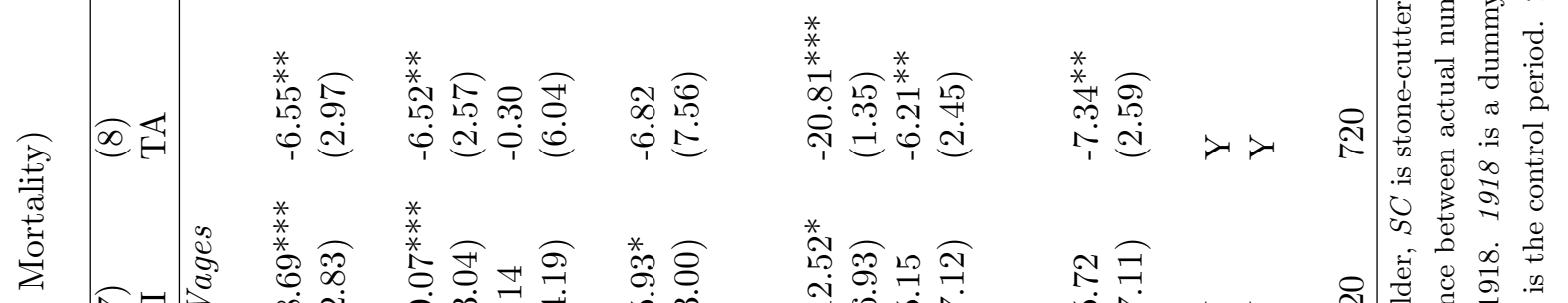

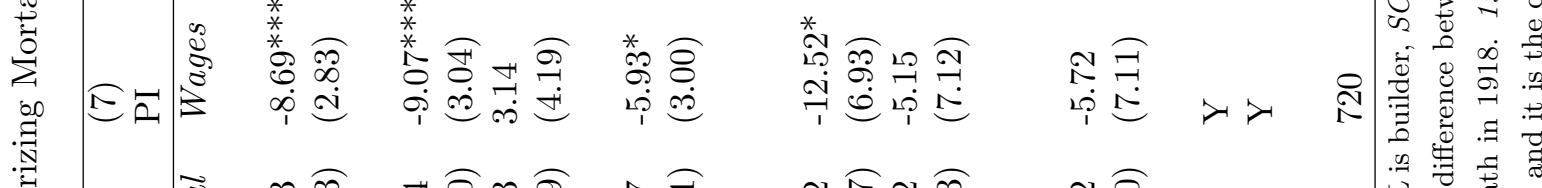

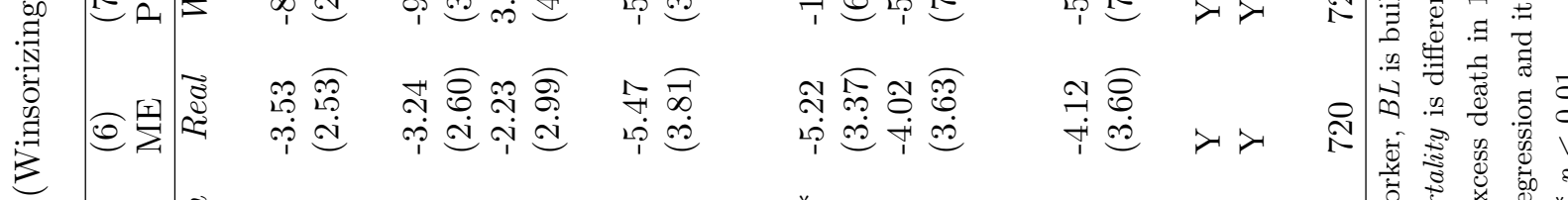

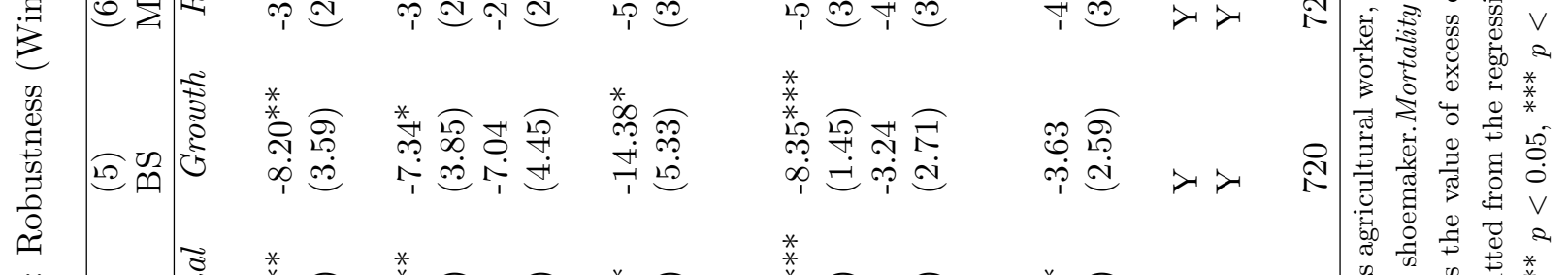

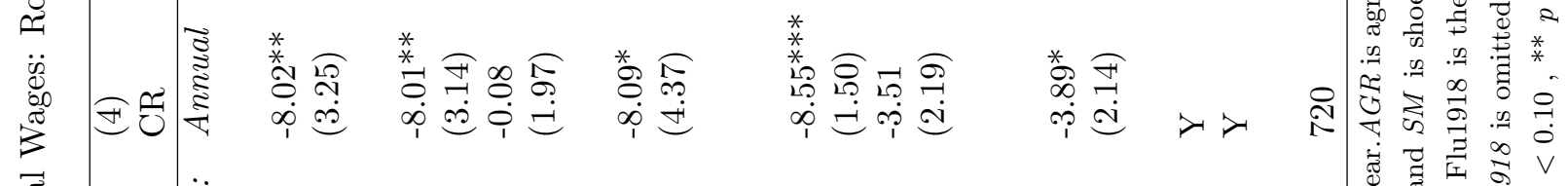

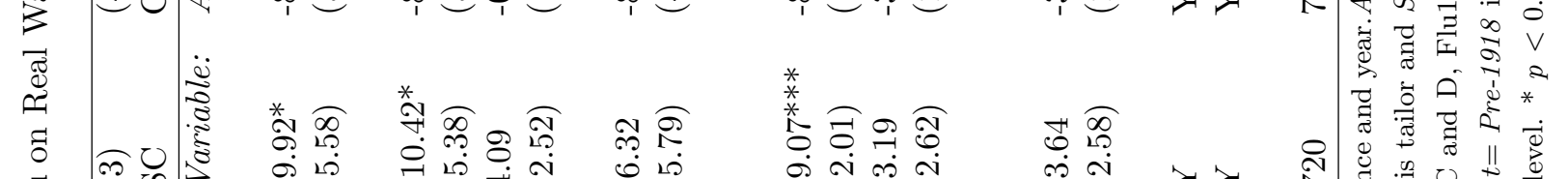

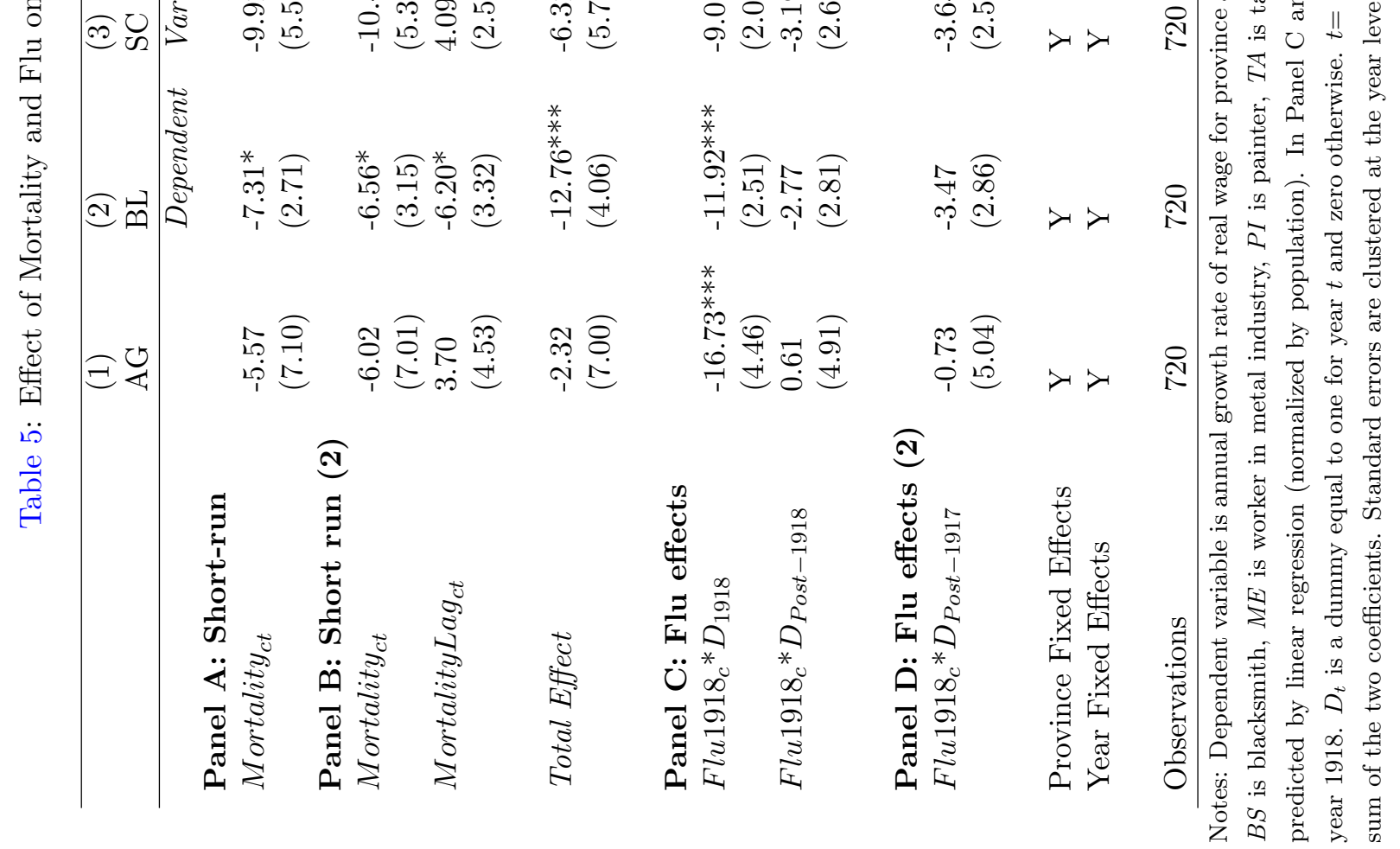




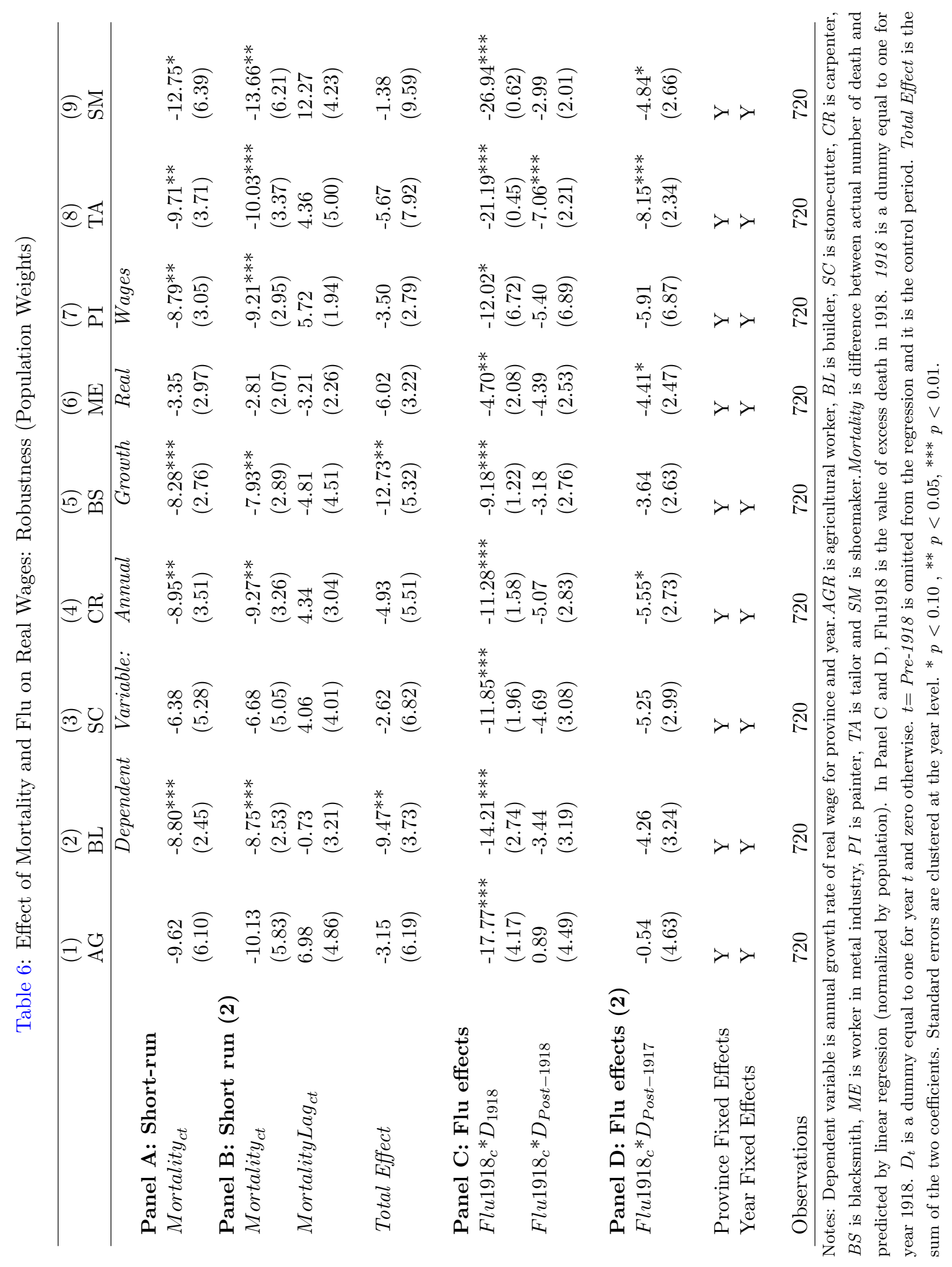




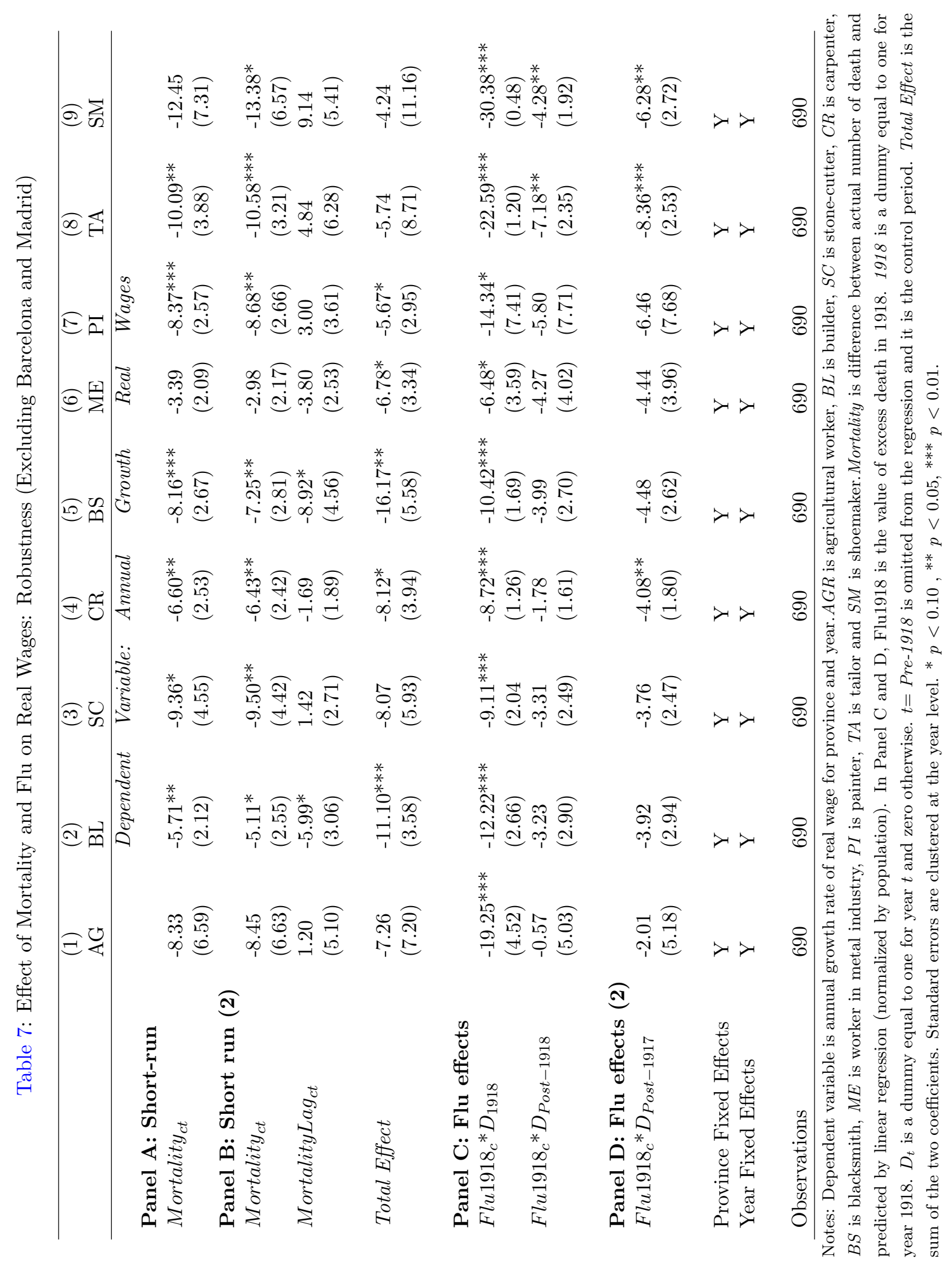




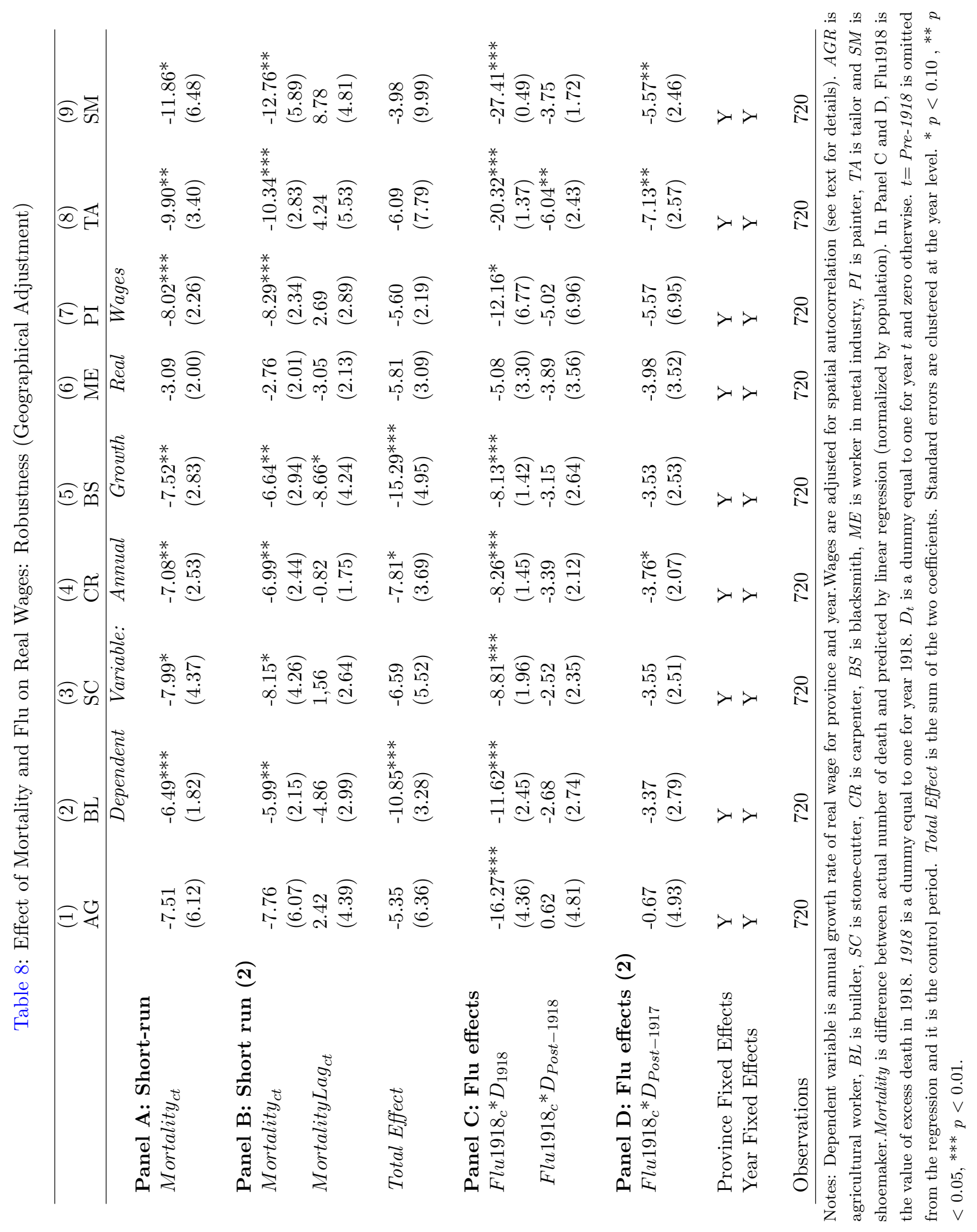




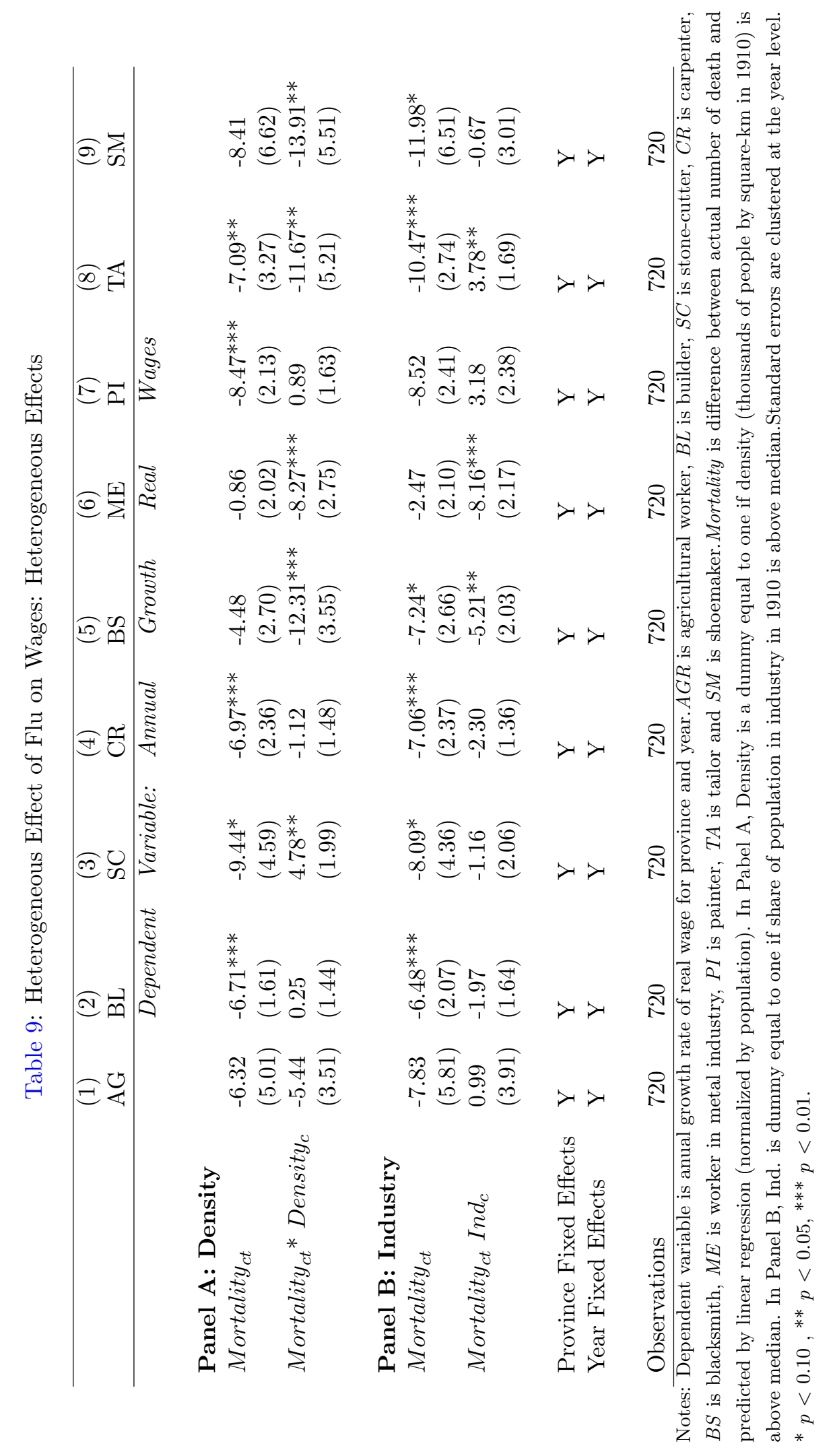




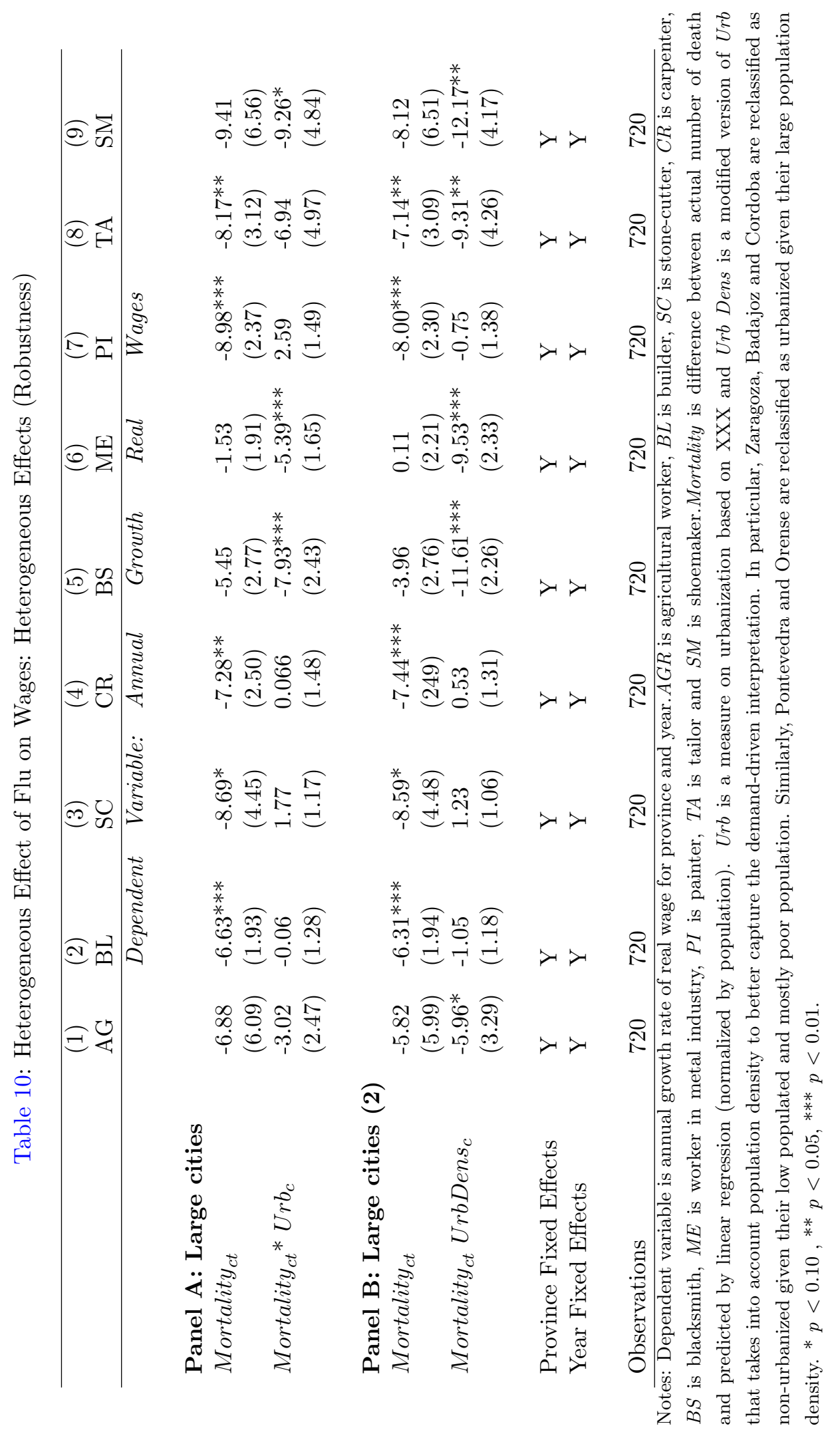


Table 11: Effects of the Flu on Rents

\begin{tabular}{lllll}
\hline & $(1)$ & $(2)$ & $(3)$ & $(4)$ \\
& Dividends & Urban & Land & Land \\
\hline Panel A: Short-run & Dep. & Var. & Annual & Growth \\
Mortalityct & & & & \\
& 8.15 & -6.70 & 1.44 & 13.47 \\
& $(23.86)$ & $(16.03)$ & $(11.59)$ & $(12.10)$
\end{tabular}

Panel B: Short-run (2)

Mortality ${ }_{c t}$

$\begin{array}{llll}5.57 & -7.35 & -0.02 & 12.66 \\ (35.85) & (15.34) & (11.11) & (11.65) \\ 32.46 & 6.32 & 14.21 & 10.97 \\ (31.76) & (13.62) & (11.42) & (16.38)\end{array}$

Total Effect

$38.04 \quad-1.02 \quad 14.19 \quad 23.64$

$\begin{array}{llll}(62.46) & (25.65) & (18.03) & (23.08)\end{array}$

Panel C: Flu Effects

$\begin{array}{lllll}\text { Flu1918 }{ }^{*} D_{1918} & -1.82 & 9.03 & -8.44^{* *} & 9.83 \\ & (32.25) & (15.99) & (3.52) & (8.40) \\ \text { Flu1918 }{ }^{*} D_{\text {Post-1918 }} & 57.62 & 7.54 & -9.15 & -6.88 \\ & (32.25) & (17.36) & (8.94) & (13.49)\end{array}$

Panel D: Flu Effects (2)

Flu1918 ${ }^{*} D_{\text {Post-1917 }}$

$\begin{array}{llll}27.99 & 7.66 & -9.09 & -5.60\end{array}$

$\begin{array}{llll}(40.89) \quad(17.15) & (8.36) \quad(12.93)\end{array}$

$\begin{array}{llllll}\text { Province Fixed Effects } & Y & Y & Y & \text { Y }\end{array}$

$\begin{array}{lllll}\text { Year Fixed Effects } & \text { Y } & \text { Y } & \text { Y } & \text { Y }\end{array}$

$\begin{array}{lllll}\text { Observations } & 281 & 720 & 720 & 720\end{array}$

Notes: Dependent variable in columns 1, 2 and 3-4 are annual growth rate of dividends, urban house prices and land, respectively. In column 4 , weighted regression with population weights. Mortality is difference between actual number of death and predicted by linear regression (normalized by population). See text for more details. Standard errors are clustered at the year level. ${ }^{*} p<0.10,{ }^{* *} p<0.05,{ }^{* * *} p<0.01$. 
Table 12: Province Characteristics (1910)

\begin{tabular}{|c|c|c|c|}
\hline Province & Population & Industry & Density \\
\hline Álava & 97181 & 5.53 & 31.92 \\
\hline Albacete & 264698 & 3.92 & 17.81 \\
\hline Alicante & 497616 & 5.70 & 85.81 \\
\hline Almería & 380702 & 2.33 & 43.34 \\
\hline Ávila & 208863 & 1.83 & 25.95 \\
\hline Badajoz & 593206 & 4.38 & 27.15 \\
\hline Baleares & 331136 & 9.01 & 63.02 \\
\hline Barcelona & 1162521 & 15.04 & 148.46 \\
\hline Burgos & 346934 & 1.75 & 24.14 \\
\hline Cáceres & 398641 & 2.70 & 19.88 \\
\hline Cádiz & 488347 & 7.25 & 64.19 \\
\hline Castellón & 322391 & 5.17 & 48.36 \\
\hline Ciudad Real & 379674 & 4.11 & 19.24 \\
\hline Córdoba & 499205 & 3.89 & 36.34 \\
\hline Coruna & 680225 & 4.20 & 85.63 \\
\hline Cuenca & 269634 & 2.54 & 15.88 \\
\hline Girona & 322523 & 10.49 & 54.51 \\
\hline Granada & 522695 & 3.51 & 41.71 \\
\hline Guadalajara & 209352 & 2.02 & 17.17 \\
\hline Guipúzcoa & 226684 & 13.32 & 120.28 \\
\hline Huelva & 310028 & 4.01 & 30.74 \\
\hline Huesca & 248299 & 3.07 & 16.39 \\
\hline Jaén & 526718 & 3.11 & 39.07 \\
\hline León & 396122 & 1.35 & 25.72 \\
\hline Lleida & 284971 & 3.25 & 23.45 \\
\hline Logrono & 188235 & 5.81 & 37.34 \\
\hline Lugo & 479965 & 1.02 & 48.58 \\
\hline Madrid & 885248 & 4.59 & 109.8 \\
\hline Málaga & 523487 & 3.76 & 71.85 \\
\hline Murcia & 615146 & 2.59 & 54.35 \\
\hline Navarra & 313235 & 3.99 & 31.40 \\
\hline Orense & 414216 & 2.23 & 58.97 \\
\hline Ovideo & 685131 & 1.74 & 62.89 \\
\hline Palencia & 196053 & 3.07 & 23.85 \\
\hline Pontevedra & 495644 & 3.79 & 112.8 \\
\hline Salamanca & 334377 & 3.13 & 27.14 \\
\hline Santander & 302956 & 3.09 & 55.49 \\
\hline Segovia & 167747 & 3.03 & 24.16 \\
\hline Sevilla & 597031 & 5.12 & 42.16 \\
\hline Soria & 156354 & 1.92 & 15.16 \\
\hline Tarragona & 340019 & 5.33 & 52.15 \\
\hline Teruel & 243556 & 2.70 & 17.24 \\
\hline Toledo & 413217 & 3.19 & 26.95 \\
\hline Valencia & 884298 & 5.29 & 80.7 \\
\hline Valladolid & 284791 & 3.79 & 34.82 \\
\hline Vizcaya & 349923 & 6.65 & 161.59 \\
\hline Zamora & 272976 & 1.73 & 25.82 \\
\hline Zaragoza & 452100 & 3.91 & 26.77 \\
\hline
\end{tabular}

